\title{
Angiotensin II Contributes to Podocyte Injury by Increasing TRPC6 Expression via an NFAT-Mediated Positive Feedback Signaling Pathway
}

Tom Nijenhuis, ${ }^{\star \dagger}$ Alexis J. Sloan, ${ }^{\ddagger}$ Joost G.J. Hoenderop, ${ }^{\dagger}$ Jan Flesche, ${ }^{\ddagger}$ Harry van Goor, ${ }^{\S}$ Andreas D. Kistler, ${ }^{\ddagger}$ Marinka Bakker, ${ }^{*}$ Rene J.M. Bindels, ${ }^{\dagger}$ Rudolf A. de Boer," "Clemens C. Möller, ${ }^{\ddagger}$ Inge Hamming, ${ }^{\S}$ Gerjan Navis," Jack F.M. Wetzels, ${ }^{*}$ Jo H.M. Berden, ${ }^{*}$ Jochen Reiser, ${ }^{\ddagger}$ Christian Faul, ${ }^{\ddagger}$ and Johan van der Vlag*

From the Departments of Nephrology* and Physiology, ${ }^{\dagger}$ Radboud University Nijmegen Medical Centre, Nijmegen, the Netherlands; the Division of Nephrology and Hypertension, ${ }^{\ddagger}$ Department of Medicine, University of Miami Miller School of Medicine, Miami, Florida; and the Departments of Pathology, ${ }^{\varsigma}$ Cardiology, ${ }^{\text {TI }}$ and Nephrology," University Medical Centre Groningen, Groningen, the Netherlands

The transient receptor potential channel C6 (TRPC6) is a slit diaphragm-associated protein in podocytes involved in regulating glomerular filter function. Gain-of-function mutations in TRPC6 cause hereditary focal segmental glomerulosclerosis (FSGS), and several human acquired proteinuric diseases show increased glomerular TRPC6 expression. Angiotensin II (AngII) is a key contributor to glomerular disease and may regulate TRPC6 expression in nonrenal cells. We demonstrate that AngII regulates TRPC6 mRNA and protein levels in cultured podocytes and that AngII infusion enhances glomerular TRPC6 expression in vivo. In animal models for human FSGS (doxorubicin nephropathy) and increased renin-angiotensin system activity (Ren2 transgenic rats), glomerular TRPC6 expression was increased in an AngII-dependent manner. TRPC6 expression correlated with glomerular damage markers and glomerulosclerosis. We show that the regulation of TRPC6 expression by AngII and doxorubicin requires TRPC6-mediated $\mathrm{Ca}^{2+}$ influx and the activation of the $\mathrm{Ca}^{2+}$-dependent protein phosphatase calcineurin and its substrate nuclear factor of activated $T$ cells (NFAT). Accordingly, cal- cineurin inhibition by cyclosporine decreased TRPC6 expression and reduced proteinuria in doxorubicin nephropathy, whereas podocyte-specific inducible expression of a constitutively active NFAT mutant increased TRPC6 expression and induced severe proteinuria. Our findings demonstrate that the deleterious effects of AngII on podocytes and its pathogenic role in glomerular disease involve enhanced TRPC6 expression via a calcineurin/NFAT positive feedback signaling pathway. (Am J Pathol 2011, 179:1719-1732; DOI: 10.1016/j.ajpath.2011.06.033)

The glomerular capillary filtration barrier consists of endothelial cells, glomerular basement membrane (GBM), and visceral epithelial cells or podocytes linked by the slit diaphragm. The slit diaphragm is a complex of interconnected proteins that connect podocyte foot processes, which provides both physical linkage and a signaling unit that regulates podocyte behavior. ${ }^{1}$ Damage to the glomerular capillary filter, in particular at the level of the podocyte and the slit diaphragm, is of crucial importance in the pathophysiology of proteinuria. ${ }^{1}$ Previously, the transient receptor potential channel C6 (TRPC6) has been identified as a novel slit diaphragm-associated pro-

Supported by a Kolff Career Stimulation Grant from the Dutch Kidney Foundation (KJPB 07.0001), a grant from the Genzyme Renal Innovations Program and a Ruby Diabetes Research Grant (2009.80.118) (T.N.), a EURYI award (J.H.), a grant from the Swiss National Science Foundation (PBZHP3-128278) and an Amgen-FROMO fellowship (A.D.K.), grants from the US National Institutes of Health (grants DK073495 and DK089394) (J.R.), and a Young Investigator Career Development Grant from the NephCure Foundation and a National Scientist Development Grant from the American Heart Association (C.F.).

Accepted for publication June 10, 2011.

T.N., A.J.S., J.G.J.H., and J.F. contributed equally to this work.

Address reprint requests to Johan van der Vlag, Ph.D., Nephrology Research Laboratory (279), Nijmegen Centre for Molecular Life Sciences, Department of Nephrology, Radboud University Nijmegen Medical Centre, P.O. Box 9101, 6500 HB Nijmegen, The Netherlands; or Christian Faul, Ph.D., Division of Nephrology and Hypertension, Leonard Miller School of Medicine, University of Miami, 1580 NW 10 th $^{\text {th }}$ Ave. (R-762), Miami, FL 33136. E-mail: J.vanderVlag@nier.umcn.nl or cfaul@med.miami.edu. 
tein in podocytes. ${ }^{2}$ Gain-of-function mutations in TRPC6 have been shown to cause autosomal dominant focal segmental glomerulosclerosis (FSGS), and enhanced podocyte expression of wild-type and mutant TRPC6 leads to glomerular damage. ${ }^{2-5}$

TRP channels are involved in several renal processes and diseases, ranging from tubular $\mathrm{Ca}^{2+}$ and $\mathrm{Mg}^{2+}$ reabsorption, through osmoregulation, to polycystic kidney disease. ${ }^{6-9}$ Podocytes express TRPC6, and co-immunoprecipitation studies demonstrate that TRPC 6 is associated with the slit diaphragm proteins nephrin and podocin, suggesting that TRPC6 is involved in signaling events at the slit diaphragm. 2,10 The slit diaphragm complex is mechanically and functionally linked to the actin cytoskeleton. Cytoskeletal rearrangement has been suggested to underlie foot process effacement, which is a crucial early event in the pathophysiology of proteinuria. ${ }^{4} \mathrm{Sev}-$ eral gain-of-function TRPC6 mutations have been identified in the TRPC6 encoding gene. ${ }^{2-4,11,12}$ In addition, glomerular TRPC6 expression is increased in acquired human proteinuric diseases, including nonfamilial FSGS and membranous glomerulopathy. ${ }^{4}$ Taken together, it is likely that enhanced $\mathrm{Ca}^{2+}$ influx due to an increased number of functional TRPC6 channels at the cell surface and/or enhanced channel activity compromises the structural integrity of the podocyte, leading to proteinuria.

TRPC6 is a receptor-operated cation channel, which can be activated by angiotensin II (Angll) through stimulation of the angiotensin type 1 receptor (AT1R) and secondary generation of diacylglycerol. ${ }^{3,13,14}$ Angll is a key contributor to the pathogenesis of glomerular disease, and the antiproteinuric effects of angiotensin-converting enzyme (ACE) inhibition and AT1R blockade are undisputed. ${ }^{15,16}$ In nonrenal cells, Angll activates TRPC6 currents and enhances TRPC6 transcription. ${ }^{14,17,18}$ In cardiomyocytes, Angll induces a TRPC6 and $\mathrm{Ca}^{2+}$-dependent calcineurin/nuclear factor of activated $T$ cells (NFAT) positive feedback loop, leading to increased TRPC6 transcription, driving cardiac hypertrophy. ${ }^{14,18}$ Podocytes also express both AT1R and AT2R, and Angll has detrimental effects in podocytes. ${ }^{15,16,19,20}$ Angll increases intracellular $\mathrm{Ca}^{2+}$ levels and induces changes in the actin cytoskeleton. ${ }^{21-23}$ When the AT1R is overexpressed in podocytes, transgenic rats develop podocyte damage and glomerulosclerosis. ${ }^{24}$ Furthermore, the overexpression of renin in mice induces podocyte damage and proteinuria, pathological effects that can be ameliorated by treating these transgenic animals with angiotensin receptor blockers (ARBs). ${ }^{25}$ In analogy to cardiomyocytes, Angllinduced $\mathrm{Ca}^{2+}$-calcineurin-NFAT-mediated transcription of TRPC6 could also occur in podocytes; therefore, Angll could cause an up-regulation of TRPC6 expression, which results in elevated intracellular $\mathrm{Ca}^{2+}$ levels in podocytes in acquired proteinuric disease.

The aims of this study were to determine whether Angll regulates TRPC6 expression in podocytes, to gain insight into the downstream effectors of Angll/TRPC6-mediated signaling, and to evaluate its in vivo significance in experimental proteinuric glomerular disease.

\section{Materials and Methods}

\section{Animal Studies}

Unilateral doxorubicin nephropathy was induced in rats by temporary clipping of the left renal artery and vein, followed by injection of $1.5 \mathrm{mg} / \mathrm{kg}$ of doxorubicin (SigmaAldrich, Zwijndrecht, the Netherlands) via the tail vein. After 12 minutes, when doxorubicin was cleared from the circulation, the clamp was removed. Bilateral doxorubicin nephropathy was induced by injection of $5 \mathrm{mg} / \mathrm{kg}$ of doxorubicin. Animals were treated with the ARB L158,809 (150 mg per liter of drinking water) from week 6 to 12 after induction of doxorubicin nephropathy. Additional animals received the ACE inhibitor (ACEi) lisinopril $(75 \mathrm{mg}$ per liter of drinking water) from week 6 to 18 after induction of doxorubicin nephropathy. Cyclosporine $(20 \mathrm{mg} / \mathrm{kg}$; dissolved in $0.5 \mathrm{~mL}$ of olive oil) or vehicle $(0.5 \mathrm{~mL}$ of olive oil) was administered by daily oral gavage from week 4 to 6 after doxorubicin injection. For the Angll infusion studies, Wistar rats received a continuous Angll infusion (435 ng/ $\mathrm{kg} /$ min) by subcutaneous osmotic minipumps during 3 weeks. Before termination, animals were housed in metabolic cages for 24 hours. Male homozygous TGR(mRen2)27 (Ren2 transgenic) rats and age-matched Sprague-Dawley rats were purchased from the Max Delbrück Center for Molecular Medicine (Berlin-Buch, Berlin, Germany). Wildtype and Ren2 transgenic rats were treated with a nonhypotensive dose of the ARB candesartan $(0.05 \mathrm{mg} / \mathrm{kg} / \mathrm{d})$ with osmotic minipumps (Alzet model 2004) for 4 weeks. The animal ethics committees of the Radboud University Nijmegen and the University Medical Centre Groningen approved all animal studies.

\section{Generation of Inducible Transgenic Mice Overexpressing Constitutive Active NFATC1 in Podocytes}

The transgenic TetO-HA-NFATC1 ${ }^{\text {nuc }}$ mouse line was generated in the laboratory of Dr. Gerald Crabtree and provided by Dr. Seung K. Kim (both from Stanford University, Stanford, California). ${ }^{26}$ In NFATc $1^{\text {nuc }}$, the serine residues that are dephosphorylated by calcineurin are substituted with alanine residues, rendering it constitutively nuclear, constitutively active, and insensitive to nuclear kinases. ${ }^{27}$ These single transgenic mice were mated with podocinreverse tetracycline-controlled transactivator (rtTA) mice to generate double transgenic doxycycline-inducible podocin-rtTA/TetO-HA-NFATC1 ${ }^{\text {nuc }}$ mice. $^{28}$ Transgenic $^{28}$ mice were genotyped using specific primer sets. Podocin-rtTA/TetO-HA-NFATc $1^{\text {nuc }} \mathrm{F} 1$ littermates were mated to obtain F2 double transgenic mice for experimental procedures. Transgene expression was induced in podocytes by adding doxycycline (Sigma-Aldrich; $2 \mathrm{mg} / \mathrm{mL}$ in $7 \%$ sucrose, $\mathrm{pH} \sim 5$ ) to the drinking water of 6 - to 8-week-old double transgenic mice for 4 days. Simultaneously, the mice were fed a special diet chow containing doxycycline (2000 ppm). Control animals were either single transgenic mice that also received doxycycline or double transgenic mice that received no doxycy- 
Table 1. Antibodies Used in the Study

\begin{tabular}{|c|c|c|c|c|}
\hline Antigen & Antibody & Description & Dilution & Manufacturer or reference \\
\hline TRPC6 & $\begin{array}{l}\text { ab62999 } \\
\text { ab12249 } \\
\text { ACC-017 }\end{array}$ & $\begin{array}{l}\text { Rabbit anti-rat TRPC6 } \\
\text { Rabbit anti-mouse TRPC6 } \\
\text { Rabbit anti-mouse TRPC6 }\end{array}$ & $\begin{array}{l}1: 1000 \\
1: 25-300 \\
1: 200\end{array}$ & $\begin{array}{l}\text { Abcam Plc, Cambridge, England } \\
\text { Abcam Plc, Cambridge, England } \\
\text { Alomone Laboratories, Jerusalem, Israel }\end{array}$ \\
\hline Desmin & D33 & Mouse anti-desmin & $1: 400$ & Dako, Glostrup, Denmark \\
\hline$\alpha$-SMA & $1 \mathrm{~A} 4$ & Mouse anti- $\alpha$-SMA & $1: 4000$ & Sigma-Aldrich, Zwijndrecht, the Netherlands \\
\hline HS & JM403 & $\begin{array}{l}\text { Mouse anti-rat HS: N-unsubstituted } \\
\text { Glucosamine domain }\end{array}$ & $1: 300$ & 29 \\
\hline Agrin & MI-91 & Guinea pig anti-rat agrin & $1: 800$ & 30 \\
\hline$\beta$-actin & AC-15 & Mouse anti- $\beta$-actin & $1: 10,000$ & Sigma-Aldrich, Zwijndrecht, the Netherlands \\
\hline GAPDH & $6 \mathrm{C5}$ & Mouse anti-GAPDH & $1: 10,000$ & $\begin{array}{l}\text { Calbiochem, EMD4Biosciences, San } \\
\text { Diego, CA }\end{array}$ \\
\hline
\end{tabular}

cline but normal chow and $7 \%$ sucrose in the drinking water. Induction of NFATc $1^{\text {nuc }}$ expression in isolated glomeruli was monitored by RT-PCR using DNasetreated total RNA and NFATc $1^{\text {nuc }}$ specific primers.

\section{Immunohistochemistry}

Glomerular expression of TRPC6 and other proteins was determined by semiquantitative scoring of immunofluorescence staining in $2-\mu \mathrm{m}$ cryosections. We first verified our immunofluorescence method detecting TRPC6 expression in the passive Heymann nephritis rat model, in which enhanced glomerular TRPC6 expression was previously shown. TRPC6 was detected using two polyclonal antibodies directed against different epitopes in TRPC6 (Table 1): a rabbit polyclonal antibody against the $\mathrm{C}$-terminal tail of rat TRPC 6 and a rabbit polyclonal antibody directed against a conserved epitope in the $\mathrm{N}$-terminal tail of mouse and rat TRPC6. Alexa-conjugated secondary antibodies were used subsequently. Both TRPC6 antibodies detected low levels of TRPC6 in the glomerulus of control animals, and TRPC6 expression was clearly increased in passive Heymann nephritis. Similar distribution patterns were observed using both anti-TRPC6 antibodies. When the primary antibody was omitted and only the secondary antibody was applied, no immunolabeling could be observed.

Glomerular TRPC6 expression was scored semiquantitatively from 0 to 5 based on the extent of TRPC 6 immunofluorescence staining in the glomerulus (negative $=0$, $1 \%$ to $20 \%$ positive $=1,21 \%$ to $40 \%$ positive $=2,41 \%$ to $60 \%$ positive $=3,61 \%$ to $80 \%$ positive $=4$, and $81 \%$ to $100 \%$ positive $=5$ ). Semiquantification of other proteins was performed in a similar way. Scoring was performed independently by two investigators, who scored 35 to 50 glomeruli per animal on blinded sections. Focal glomerulosclerosis (FGS) was scored semiquantitatively on periodic acid-Schiff-stained paraffin sections in 50 glomeruli per kidney on a scale of 0 to 400 . FGS lesions were defined as glomerular areas with mesangial expansion and adhesion formation simultaneously present in one segment.

\section{Cell Culture and Transfection}

Conditionally immortalized mouse podocytes (MPC-5) were cultured as described previously. ${ }^{31}$ Differentiated podocytes were treated with doxorubicin $(0.25 \mu \mathrm{g} / \mathrm{mL})$ or puromycin aminonucleoside (PAN; $100 \mu \mathrm{g} / \mathrm{mL}$ ) for 24 hours. Depending on the exact experimental setup, Angll (1 $\mu \mathrm{mol} / \mathrm{L})$, losartan $(100 \mu \mathrm{mol} / \mathrm{L})$, captopril (1 $\mathrm{mmol} / \mathrm{L})$, chymostatin $(100 \mu \mathrm{mol} / \mathrm{L}), \mathrm{LaCl}_{3}(50 \mu \mathrm{mol} / \mathrm{L})$, 2-aminoethyldiphenylborane (2-APB) (10 $\mu \mathrm{mol} / \mathrm{L})$, and/or cyclosporine (csA) (1 $\mu \mathrm{mol} / \mathrm{L})$ was added. A podocyte cell line stably expressing TRPC 6 silencing short hairpin RNA (shRNA) was obtained after transfecting a TRPC6 shRNA construct with Lipofectamine 2000 into undifferentiated MPC-5 podocytes cultured at $33^{\circ} \mathrm{C}$ and subsequent selection in the presence of G418. Single clones were tested for TRPC6 mRNA and protein expression. Podocyte TRPC6 overexpression was achieved by lentiviral transduction of differentiated podocytes. FLAG-tagged wild-type mouse TRPC6 cDNA was cloned into the VVPW lentiviral expression vector (kind gift of G. Luca Gusella, New York, NY). Then 80\% confluent HEK 293T cells were transfected in antibiotic-free Dulbecco's modified Eagle's medium, $10 \%$ fetal bovine serum with the VVPW plasmid, and the two helper plasmids psPAX2 and pCMV-VSVG (both from Addgene, Cambridge, MA) in a ratio of 3:2:1 using FuGENE, according to the manufacturer's protocol. Control virus was produced using empty VVPW vector together with the same helper plasmids. After 16 hours, the medium was changed to Dulbecco's modified Eagle's medium and 10\% fetal bovine serum, containing penicillin and streptomycin. At 24 and 48 hours thereafter, the virus-containing cell culture supernatant was harvested and stored at $4{ }^{\circ} \mathrm{C}$, the 24 - and 48 -hour collections were pooled and centrifuged $(600 \times \mathrm{g}$; 5 minutes), and the supernatant filtered through a $0.5 \mu \mathrm{m}$ filter, aliquoted, and frozen at $-80^{\circ} \mathrm{C}$. Podocytes stably transfected with the pGL4.30 reporter plasmid expressing the luc2P firefly luciferase gene under the control of the NFAT response element (see below) were transduced with lentivirus 10 days after induction of differentiation in the presence of $4 \mu \mathrm{g} / \mathrm{mL}$ of hexadimethrine bromide for 16 hours, and NFAT activity was measured 4 days later.

\section{NFAT Reporter Assay}

To assess NFAT activity in podocytes, a reporter podocyte cell line was generated that stably expresses the pGL4.30 reporter plasmid (Promega, Madison, WI). 
pGL4.30 includes the luc2P firefly luciferase gene under the control of the NFAT response element. Stably transfected clones were selected in the presence of hygromycin $(300 \mu \mathrm{g} / \mathrm{mL})$. Cells were differentiated for 10 days before lentiviral transduction and for 14 days before drug treatment. Stable cell lines were probed with Bright-Glo Luciferase Assay System (Promega), and luminescence was measured on a SpectraMax L luminescence microplate reader (Molecular Devices, Sunnyvale, CA).

To assess NFAT activity in TRPC6 knockdown cells, undifferentiated wild-type and TRPC6 stable knockdown podocytes were transiently transfected with the pGL4.30 reporter plasmid-expressing the luc2P firefly luciferase gene under the control of the NFAT response element and the pGL4.74 plasmid-expressing hR/uc Renilla luciferase as an internal control to correct for transfection efficiency (Promega). Transiently transfected cells were assayed with Dual-Glo Luciferase Assay System (Promega).

\section{Real-Time Quantitative RT-PCR Analysis}

Total RNA was isolated from cultured podocytes and RNA was reverse transcribed (Transcriptor Kit; Roche Diagnostics, Mannheim, Germany). Real-time quantitative PCR was performed using SYBR Green Supermix (Roche Diagnostics) on a MyiQ Real-Time PCR Detection System (Bio-Rad Laboratories, Hercules, CA). TRPC6 expression was quantified by the delta-delta $\mathrm{C}_{\mathrm{T}}$ method using glyceraldehyde 3-phosphate dehydrogenase $(G A P D H)$ as the housekeeping gene. Sample sizes of 5 to 8 separate mouse podocyte cultures were used per experimental condition per experiment. Results were confirmed in at least two distinct experiments.

\section{Immunocytochemistry}

Podocytes grown on collagen A-coated plastic SlideFlasks (NUNC, Roskilde, Denmark) were fixed and incubated with a rabbit polyclonal anti-mouse TRPC6 antibody (Table 1). Alexa-conjugated secondary antibodies were applied, cells were embedded, and images were collected as described above.

\section{Immunoblotting}

Podocytes or isolated glomeruli were lysed in a 20 $\mathrm{mmol} / \mathrm{L}$ Tris $\mathrm{pH} 8$ buffer containing $500 \mathrm{mmol} / \mathrm{L} \mathrm{NaCl}$, $0.5 \%(\mathrm{wt} / \mathrm{vol}) 3$-[(3-cholamidopropyl)dimethylammonio]1-propanesulfonate (CHAPS), 1\% (vol/vol) Triton X-100, 2 pg of pepstatin, and the Complete Mini cocktail of protease inhibitors (Roche Diagnostics). Protein concentration was determined and samples containing equal amounts of protein were resolved on a 10\% (wt/vol) SDSPAGE gel and blotted to polyvinylidene difluoride membranes (Bio-Rad Laboratories). Blots were incubated with rabbit polyclonal anti-mouse TRPC6 antibody, mouse anti- $\beta$-actin antibody, or mouse anti-GAPDH antibody (Table 1) and subsequently with peroxidase-labeled sec- ondary antibodies. Proteins were visualized using chemiluminescence, and signal intensity was determined digitally.

\section{$\mathrm{Ca}^{2+}$ Imaging Studies}

Imaging of intracellular $\mathrm{Ca}^{2+}$ concentration $\left(\left[\mathrm{Ca}^{2+}\right]_{\mathrm{i}}\right)$ with Fura-2 was performed in selected populations of cells with an inverted fluorescence microscope setup. In brief, conditionally immortalized mouse podocytes expressing either a control shRNA or TRPC6 shRNA construct were incubated with $5 \mu \mathrm{mol} / \mathrm{L}$ Fura-2-AM (Sigma-Aldrich) for 45 minutes at room temperature. Cells were treated with $100 \mu \mathrm{mol} / \mathrm{L}$ 1-oleoyl-2-acetylsn-glycerolin $(\mathrm{OAG})$ in the presence or absence of 2-APB, and $\left[\mathrm{Ca}^{2+}\right]_{i}$ was measured. After stimulation, the extracellular buffer was exchanged with $2 \mathrm{mmol} / \mathrm{L}$ $\mathrm{Ca}^{2+}$ to distinguish membrane-associated channel-dependent changes in $\left[\mathrm{Ca}^{2+}\right]_{\mathrm{i}}$. Fluorescence data are presented as a 340/380-nm ratio. Data from selected cell populations were averaged, and statistical analysis was performed on multiple experiments.

\section{Statistical Analysis}

Data are expressed as mean \pm SEM. Statistical comparisons were analyzed by one-way analysis of variance and Fisher's multiple comparison. $P<0.05$ was considered significant.

\section{Results}

\section{Glomerular TRPC6 Expression Correlates with Podocyte Injury in Doxorubicin Nephropathy}

Unilateral doxorubicin nephropathy was induced and resulted in a significant proteinuria (161 $\pm 52 \mathrm{mg} / 24 \mathrm{~h}$, $246 \pm 14 \mathrm{mg} / 24 \mathrm{~h}$, and $388 \pm 28 \mathrm{mg} / 24 \mathrm{~h}$ at 6,18 , and 30 weeks, respectively, after doxorubicin injection). Glomerular TRPC6 protein expression was increased in doxorubicin-exposed kidneys when compared with control kidneys (Figure 1, A and B). TRPC6 expression and proteinuria increased over time (Figure 1B), and proteinuria tended to increase with higher TRPC6 protein levels $\left(r^{2}=0.2029 ; P=0.16\right)$ (Figure $\left.1 C\right)$. FGS as a direct measure of glomerular injury was significantly increased in doxorubicin-exposed kidneys ( $8 \pm 3$ versus $1 \pm 1$ at 6 weeks, $47 \pm 11$ versus $12 \pm 4$ at 18 weeks, and $89 \pm 24$ versus $33 \pm 7$ at 30 weeks). The FGS score correlated with TRPC6 protein levels $\left(r^{2}=0.8028 ; P<0.0001\right)$ (Figure 1D). TRPC6 expression was also enhanced in bilateral doxorubicin nephropathy (Figure 1E), as were cortical TRPC6 mRNA levels (Figure 1F), suggesting that doxorubicin nephropathy alters transcription of TRPC6. In glomeruli from doxorubicin nephropathy rats, TRPC6 co-localized with desmin, which is a marker for injured podocytes, whereas in control kidneys desmin and TRPC6 expression levels were low (Figure 1G). No co-localization was found for TRPC6 and glomerular $\alpha$-smooth muscle actin ( $\alpha$-SMA), which 

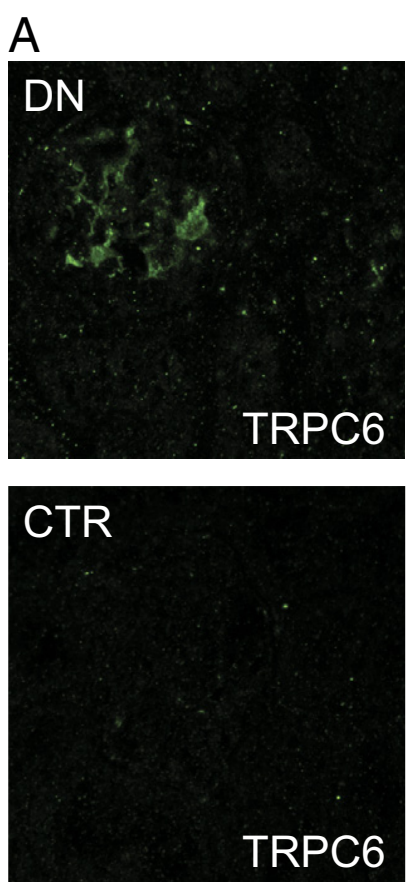
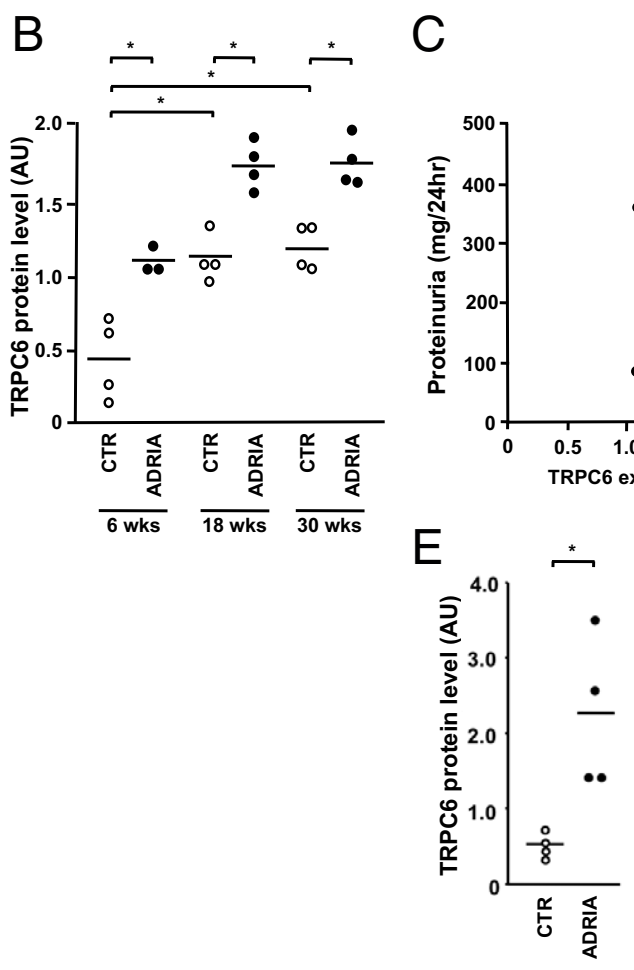

$\mathrm{D}$

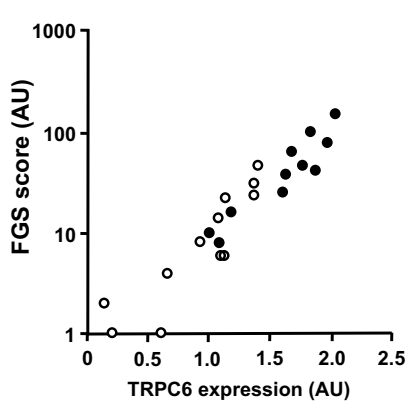

$\mathrm{F}$

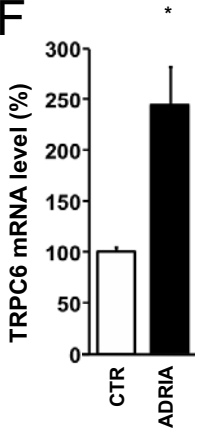

\section{G}
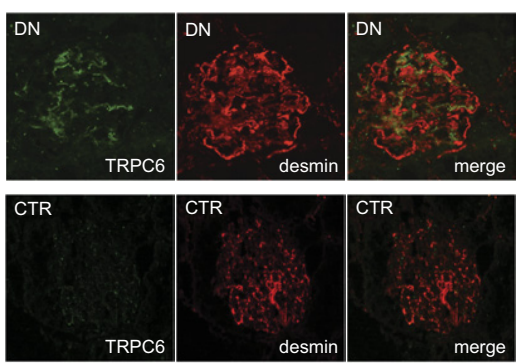
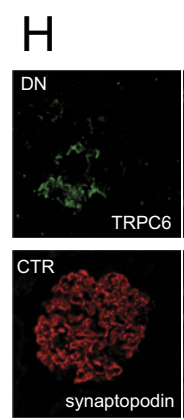
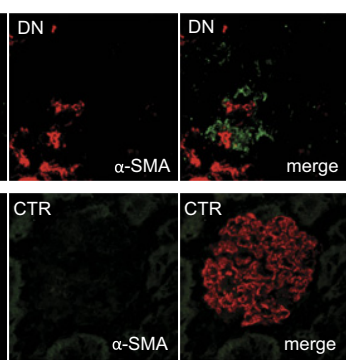
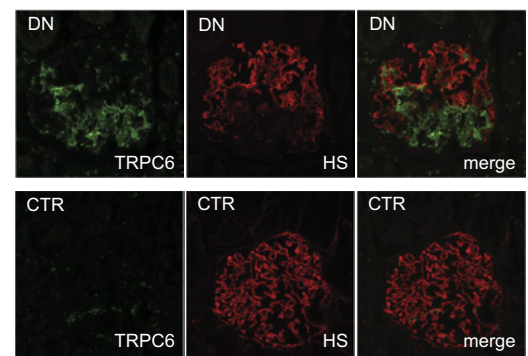

Figure 1. Glomerular TRPC6 expression in the doxorubicin nephropathy (DN) rat model. Representative images of glomerular immunolabeling for TRPC6 in control rats (CTR) and rats with DN (A). TRPC6 expression was determined by semiquantitative analyses of immunofluorescence signals in doxorubicin (DOXO)-exposed and contralateral control (CTR) kidneys, 6, 18, and 30 weeks after treatment (B). Correlation between glomerular TRPC6 expression in the DOXO-exposed kidney and proteinuria in the unilateral DN model (C). Correlation between semiquantitative scoring for TRPC6 protein level and the FGS score in DOXO-exposed (closed dots) and contralateral control (open dots) kidneys (D). TRPC6 protein (E) and mRNA levels (F) in bilateral DN. Co-localization studies for TRPC6 with the marker for injured podocytes desmin $(\mathbf{G})$, the mesangial injury marker $\alpha$-SMA $(\mathbf{H})$, or HS in the GBM (I). ${ }^{*} P<0.05$.

is a mesangial injury marker (Figure $1 \mathrm{H})$. However, $\alpha$-SMA and TRPC6 were expressed in similar glomerular segments in doxorubicin nephropathy, whereas $\alpha$-SMA expression was negative in control kidneys. Because controls show, as expected, no $\alpha$-SMA expression and low TRPC6 expression, we included co-staining of synaptopodin with $\alpha$-SMA instead as a control. To further study the relationship between glomerular damage and TRPC6 expression, we performed co-stainings of TRPC6 with the heparan sulfate (HS) antibody JM403, which recognizes $\mathrm{N}$-unsubstituted HS moieties present in the GBM. Immunostaining for HS in the GBM was linear in control animals, but in glomerular areas with high TRPC6 expression in doxorubicin nephropathy, HS staining was reduced and aberrantly distributed (Figure 1I).

\section{ARBs Prevent the Increase of TRPC6 Expression During Podocyte Injury in Vivo and in Vitro}

Because of the proposed role for Angll in doxorubicininduced glomerular injury, we evaluated the effect of ARBs on TRPC6 expression in glomeruli. When rats with bilateral doxorubicin nephropathy were treated with an ARB, glomerular TRPC6 levels were reversed to levels of untreated control animals (Figure 2, A and B). Doxorubicin exposure did not alter blood pressure, whereas ARB treatment significantly reduced blood pressure (Figure $2 \mathrm{C}$ ) and ameliorated proteinuria (245 $\pm 43 \mathrm{mg} / 24 \mathrm{~h}$ versus $697 \pm 94 \mathrm{mg} / 24 \mathrm{~h}$ ). ARBs reduced glomerular injury as indicated by the FGS 
A
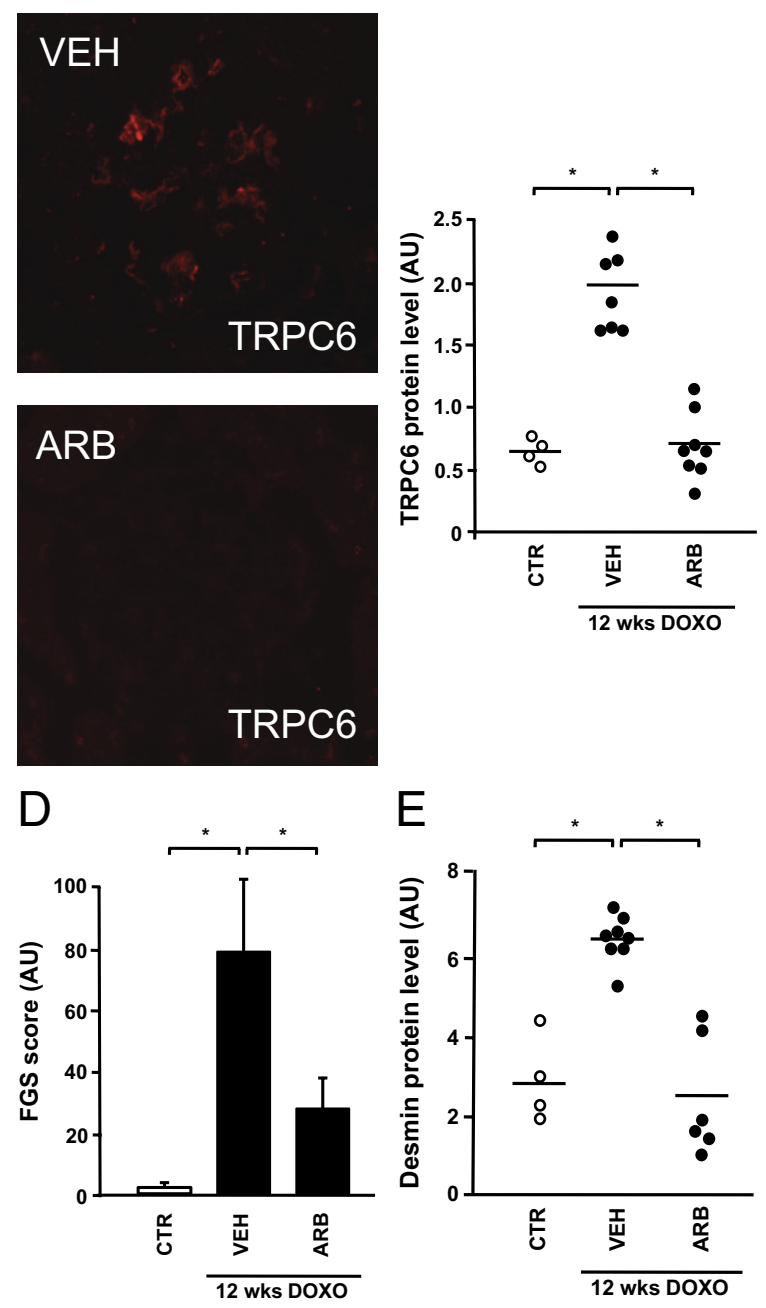

C
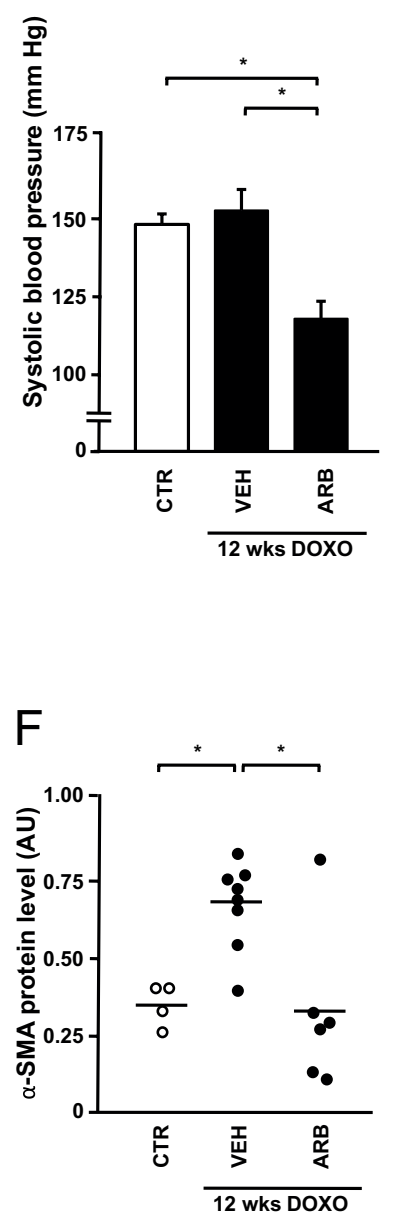

Figure 2. Effect of angiotensin receptor blockade on glomerular TRPC6 expression in bilateral doxorubicin nephropathy. Glomerular TRPC6 expression was determined semiquantitatively in control animals (CTR), vehicle-treated doxorubicin nephropathy rats (VEH), and L158,809treated doxorubicin nephropathy rats (ARB) (A and $\mathbf{B}$ ). In addition, blood pressure (C), the FGS score (D), expression of the podocyte injury marker desmin (E), and the mesangial injury marker $\alpha$-SMA (F) were determined in the respective groups. DOXO, doxorubicin. ${ }^{*} P<0.05$. score (Figure 2D), as well as glomerular desmin (Figure 2E) and $\alpha$-SMA protein levels (Figure 2F). We also studied TRPC6 expression in PAN- and doxorubicininduced podocyte injury in vitro. Enhanced TRPC6 expression has been previously demonstrated in PANtreated cultures podocytes. ${ }^{2,10}$ Indeed, PAN treatment of immortalized mouse podocytes significantly increased TRPC6 mRNA levels, which was ameliorated by co-incubation with the ARB losartan (Figure 3A). In addition to the evaluation of glomerular TRPC6 levels in the in vivo doxorubicin nephropathy rat model, we also studied TRPC6 expression in doxorubicin-treated podocytes in vitro. Doxorubicin also increased TRPC6 mRNA levels in cultured podocytes, which was partially prevented by ARB co-incubation (Figure 3B). To ascertain whether these transcriptional changes resulted in alterations of TRPC6 protein levels, we performed immunocytochemistry (Figure 3C) and immunoblot analyses (Figure 3D). Quantitative analyses of immunoblots showed that doxorubicin increased TRPC6 protein expression in podocytes, which was inhibited by ARB co-incubation (Figure 3E). Furthermore, ARB preincubation in addition to co-incubation completely prevented the doxorubicin-induced TRPC6 up-regulation (Figure 3F).

\section{Elevated Angll Levels Increase TRPC6 Expression in Vitro and in Vivo}

Because the data described above suggest that Angll could be an important mediator of TRPC6 expression in the podocyte, we evaluated whether in vivo and in vitro Angll application affected TRPC6 expression. When rats were infused with Angll during 21 days, semiquantitative immunohistochemistry demonstrated significantly enhanced glomerular TRPC6 expression (Figure 4A), accompanied by a mild proteinuria $(110 \pm 27 \mathrm{mg} / 24 \mathrm{~h}$ versus $15 \pm 1 \mathrm{mg} / 24 \mathrm{~h}$ in controls). Similarly, when podocytes were cultured in the presence of Angll, TRPC6 mRNA levels were increased (Figure 4B). Subsequently, we studied glomerular TRPC6 expression in Ren2 transgenic rats, an animal model for Angll-mediated glomerular and tubulointerstitial injury. ${ }^{32}$ Glomerular TRPC6 expression was significantly increased in Ren2 transgenic rats, whereas treatment with the $A R B$ 

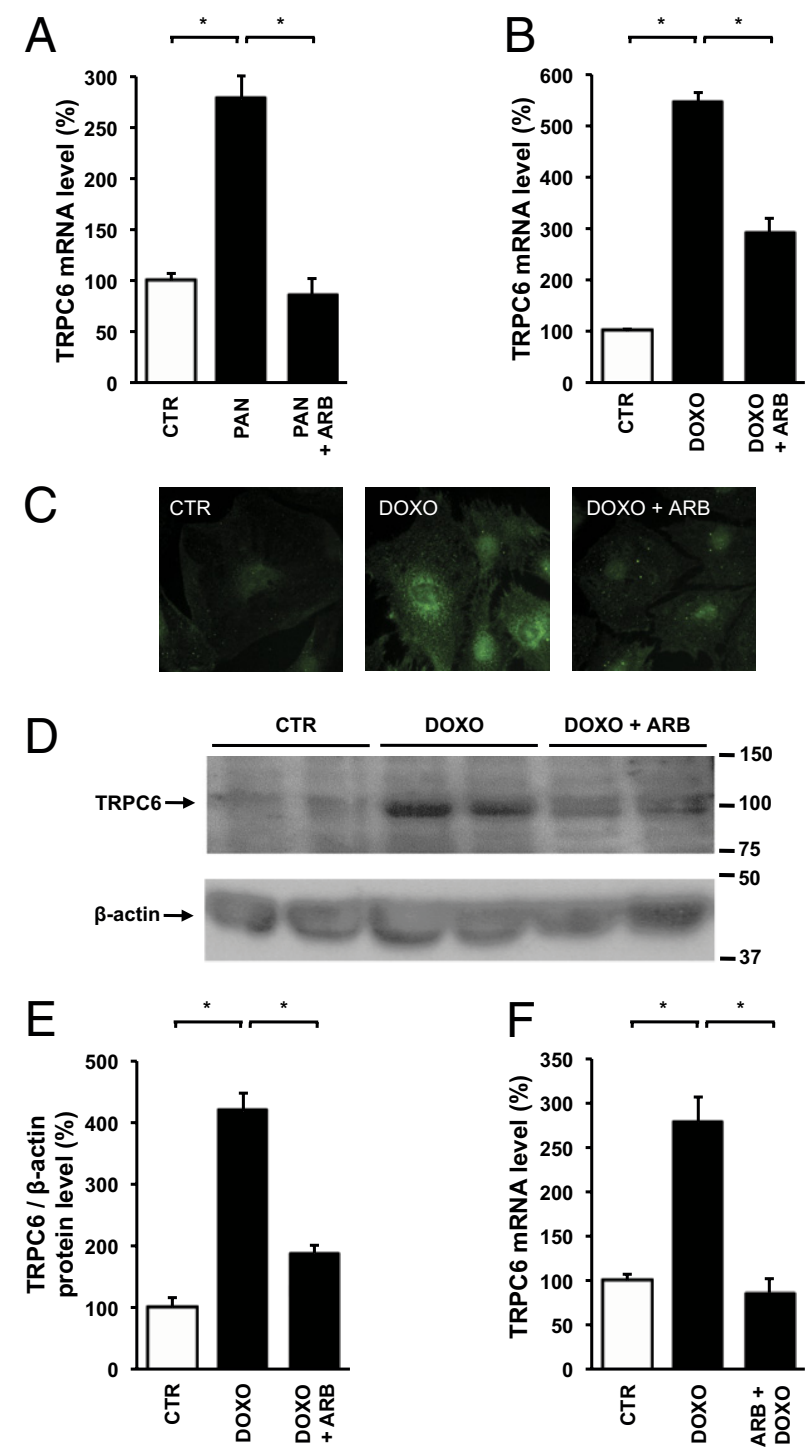

Doxo DOXO + ARB

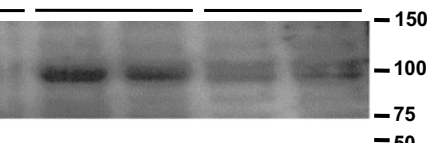

5

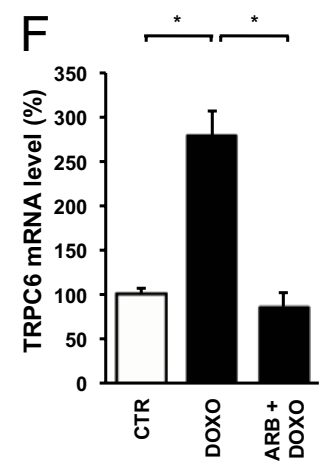

Figure 3. Effect of angiotensin receptor blockade on TRPC6 mRNA and protein levels in in vitro podocyte injury. TRPC6 mRNA levels were determined in untreated cultured podocytes (CTR) and podocytes incubated for 24 hours with PAN or co-incubated with losartan (PAN + ARB) $(n=5-6$ separate podocyte cultures per experimental condition) (A). The effect of doxorubicin (DOXO) and co-incubation with DOXO and losartan (DOXO + ARB) on TRPC6 mRNA levels (B). TRPC6 protein expression visualized by immunocytochemistry of cultured podocytes (C). Immunoblot analysis of cell lysates derived from DOXO- and/or losartan-treated podocytes for TRPC6 and $\beta$-actin. Molecular weights indicated in kiloDaltons.(D). Intensity of TRPC6 immunoblot signals was quantified by densitometry and TRPC6 protein levels were normalized to $\beta$-actin $(\mathbf{E})$. Effect of preincubation with ARB 1 hour before DOXO application (ARB + DOXO) on TRPC6 mRNA levels $(\mathbf{F}) .{ }^{*} P<0.05$.

candesartan in a nonhypotensive dose significantly reduced this effect (Figure 4C). This finding suggests that increased TRPC6 expression in Ren2 transgenic rats is Angll dependent. Alternatively, a direct effect of renin on TRPC6 expression via the (pro)renin receptor that is expressed by podocytes could cause this finding. ${ }^{33}$ However, renin application to differentiated cultured podocytes did not induce TRPC6 expression (Figure 4D). Because our results suggest that Angll regulates TRPC6 expression in podocyte injury, we evaluated the effect of lowering Angll levels in bilateral doxorubicin nephropathy. The ACEi lisinopril significantly decreased glomerular TRPC6 expression (Figure 4E). ACEi also decreased blood pressure (Figure 4F), proteinuria (289 $\pm 77 \mathrm{mg} / 24 \mathrm{~h}$ vs $641 \pm 91 \mathrm{mg} / 24$ h), and the FGS score (Figure 4G). Podocytes also harbor a local renin-angiotensin-aldosterone system (RAAS), whose components are synthesized on podocyte injury. ${ }^{34,35}$ However, high concentrations of the ACEi captopril and/or chymostatin, an inhibitor of nonACE-mediated Angll production, did not affect doxorubicin-induced TRPC6 expression in cultured podocytes (Figure 4H), suggesting that injury-induced Angll production by the podocyte itself is not involved.

\section{Angll and Doxorubicin-Induced Increase of TRPC6 Expression Involves Calcineurin/NFAT Signaling}

Next we evaluated whether the downstream signaling events of Angll-induced AT1R activation in podocytes involve the $\mathrm{Ca}^{2+}$-dependent calcineurin/NFAT pathway, as it does in other cell types. ${ }^{14,18}$ We demonstrated that calcineurin inhibition through application of cyclosporine prevented both doxorubicin- (Figure 5A) and Angll-induced (Figure 5B) TRPC6 expression. In other cell types it is well established that activated calcineurin dephosphorylates the transcription factor NFAT, thereby enhancing transcription of NFAT-responsive genes, including TRPC6. ${ }^{14,36}$ To analyze NFAT activity in podocytes, we used a reporter system driving luciferase expression under the control of an NFAT-responsive element. PAN administration, which increased TRPC6 expression, enhanced NFAT activation, whereas this effect was attenuated by the calcineurin inhibitors cyclosporine and tacrolimus (Figure 5C). Similarly, doxorubicin administration significantly enhanced NFAT activation, whereas cyclosporine or ARB treatment attenuated the doxorubicininduced NFAT-controlled luciferase expression (Figure 5D). Angll treatment also enhanced NFAT-controlled luciferase expression in podocytes, and, again, both cyclosporine and ARB treatment were able to block this effect (Figure 5E). In cardiomyocytes, $\mathrm{Ca}^{2+}$ influx through TRPC6 itself induces NFAT-mediated TRPC6 transcription. ${ }^{14}$ We demonstrate that in the podocyte, enhancing TRPC6 expression through lentiviral infection with a TRPC6-FLAG construct (Figure 5F) resulted in enhanced NFAT activation (Figure 5G). In line with our hypothesis, cyclosporine administration blocked the NFAT activation secondary to exogenous TRPC6 overexpression (Figure 5G). Substantiating the in vivo significance of these in vitro findings, cyclosporine also significantly decreased doxorubicin-induced glomerular TRPC6 expression (Figure $5 \mathrm{H}$ ) and albuminuria in rats $(178 \pm 58 \mathrm{mg} / 24 \mathrm{~h}$ versus $311 \pm 46 \mathrm{mg} / 24 \mathrm{~h})$.

To study the $\mathrm{Ca}^{2+}$ influx dependency of this mechanism, we demonstrated that when doxorubicin-challenged podocytes were treated with $\mathrm{LaCl}_{3}$, which is a general blocker of $\mathrm{Ca}^{2+}$ influx across cell membranes, TRPC6 mRNA levels were significantly decreased (Figure 6A). Furthermore, the TRPC channel blocker 2-APB inhibited doxorubicin- 

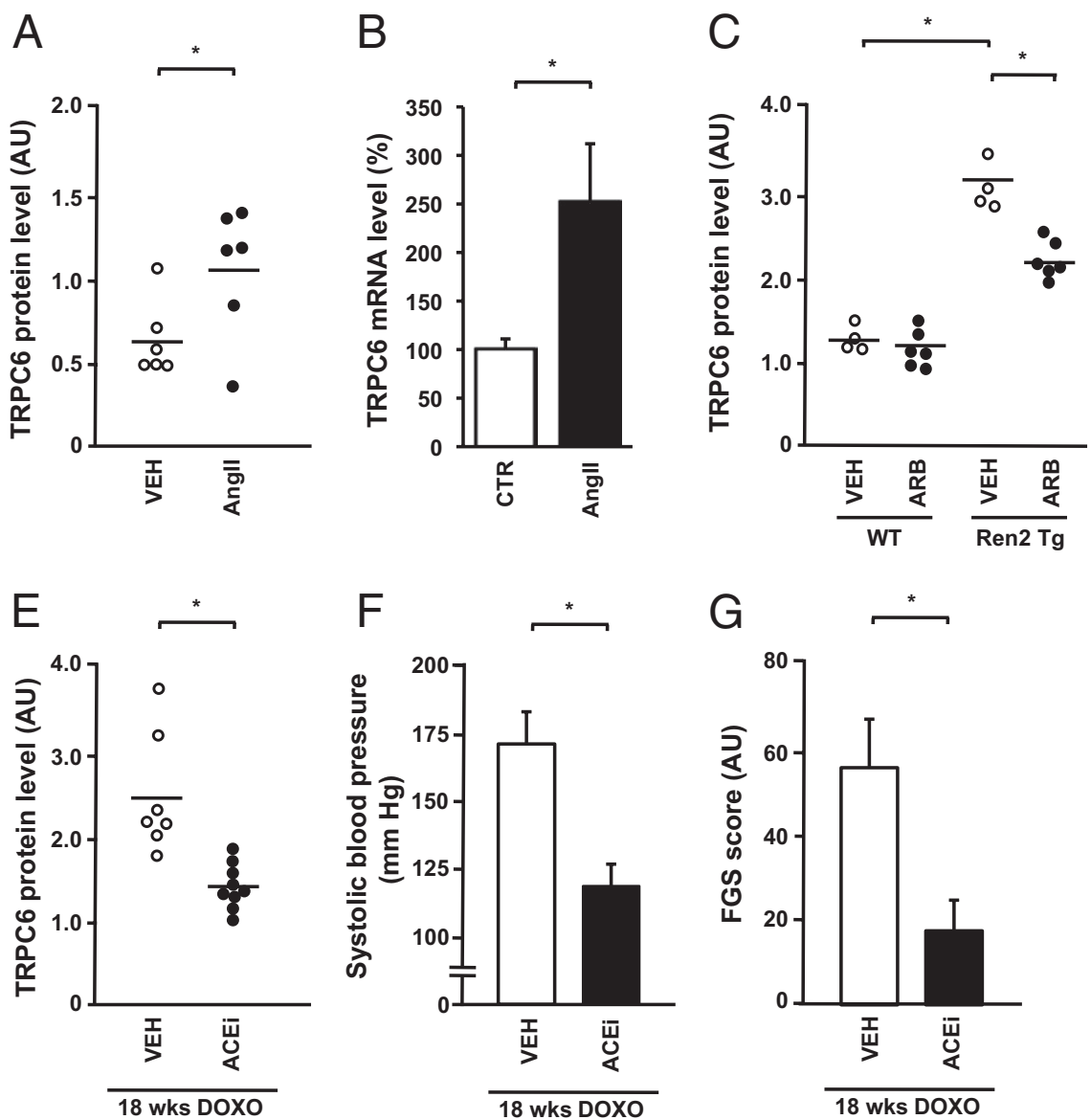
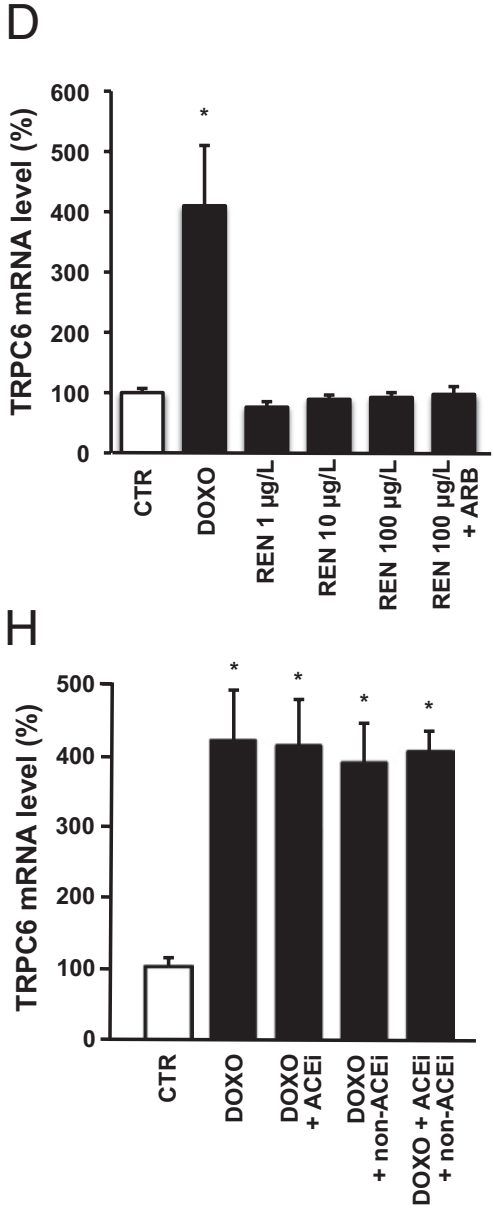

Figure 4. Effects of AngII, ARBs, ACEis, and renin on TRPC6 expression in podocytes in vitro and in vivo. Glomerular TRPC6 expression was determined by semiquantitative analyses of immunofluorescence signals in vehicle-treated (VEH) and AngII-treated rats (A). TRPC6 mRNA levels in untreated differentiated cultured podocytes (CTR) and podocytes incubated with AngII (B). Glomerular TRPC6 expression was determined semiquantitatively by immunohistochemistry in Ren2 overexpressing transgenic (Ren2 Tg) rats and wild-type (WT) controls, which were treated with VEH or candesartan (ARB) (C). TRPC6 mRNA levels in CTR, podocytes incubated with doxorubicin (DOXO), and increasing concentrations of renin (REN) and losartan (ARB) (D). Glomerular TRPC6 expression in VEH and lisinopril-treated (ACEi) doxorubicin nephropathy rats (E). Systolic blood pressure (F) and the FGS score (G) in VEH and lisinopril-treated doxorubicin nephropathy rats. TRPC6 mRNA levels in CTR, podocytes incubated with DOXO, and DOXO-treated podocytes in the presence or absence of captopril (ACEi) and/or chymostatin as a blocker of non-ACE, chymase-mediated AngII production (non-ACEi) (H). $n=5$ to 6 separate podocyte cultures per experimental condition. ${ }^{*} P<0.05$.

(Figure 6B) and Angll-induced TRPC6 expression (Figure $6 \mathrm{C})$. Because there are no TRPC6-specific blockers available to date, we used a TRPC6 knockdown technique using TRPC6 shRNA (Figure 6D) to evaluate the effect of reduced TRPC6 expression levels on Angllinduced NFAT activation. Indeed, TRPC6 knockdown decreased Angll-induced NFAT activation in podocytes compared with control cells (Figure 6E). This indicated that TRPC6, at least in part, mediates the effect of Angll on NFAT activation. To confirm that the TRPC channel blocker 2-APB and the TRPC6 knockdown approach indeed affected receptor-mediated $\mathrm{Ca}^{2+}$ influx, we evaluated Fura-2 ratiometry secondary to stimulation by the diacylglycerol analog OAG in podocytes. Indeed, TRPC6 knockdown in podocytes resulted in reduced OAG-stimulated $\mathrm{Ca}^{2+}$ influx compared with nontransfected podocytes or cells transfected with control shRNA (Figure 6F). Furthermore, 2-APB application significantly reduced OAG-stimulated $\mathrm{Ca}^{2+}$ influx (Figure 6F). Importantly, 2-APB did so in untransfected podocytes and cells trans- fected with control shRNA but to a much lesser degree in the TRPC6 knockdown situation (Figure 6G), strongly suggesting that TRPC6 is the major TRPC channel mediating the 2-APB-sensitive $\mathrm{Ca}^{2+}$ influx in cultured podocytes.

\section{Podocyte-Specific Overexpression of Activated NFAT in Mice Increases TRPC6 Expression and Induces Proteinuria}

Our findings suggest that in podocytes TRPC6-mediated activation of NFAT enhances TRPC6 transcription and is eventually detrimental to the glomerular filter, causing proteinuria. Because doxorubicin and Angll, two inducers of podocyte damage and proteinuria in animal models, activate this pathway and TRPC6 gain-of-function mutations and overexpression underlie human glomerular disease, it is possible that NFAT activation per se induces podocyte damage. To test this hypothesis, we 

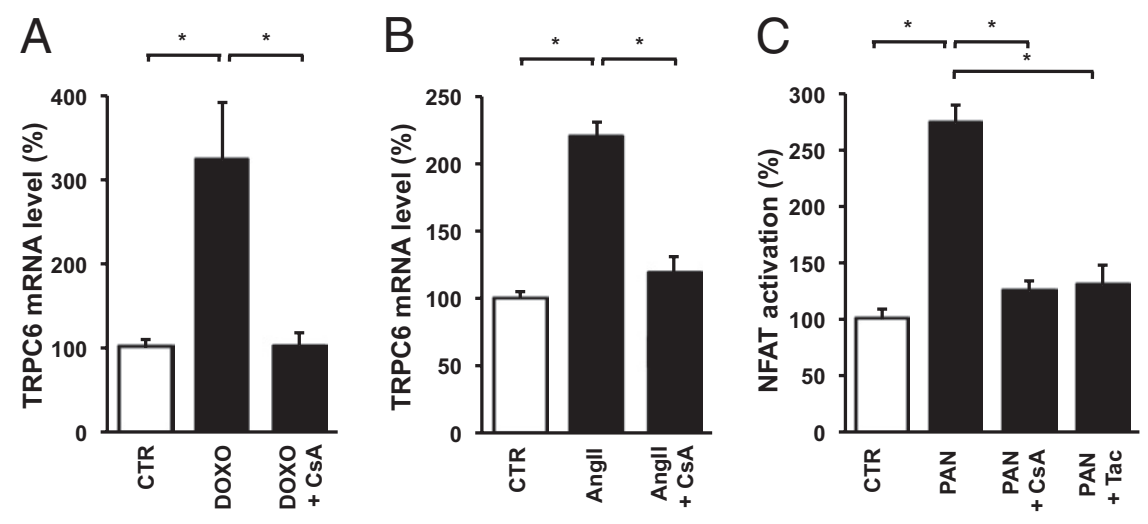

D
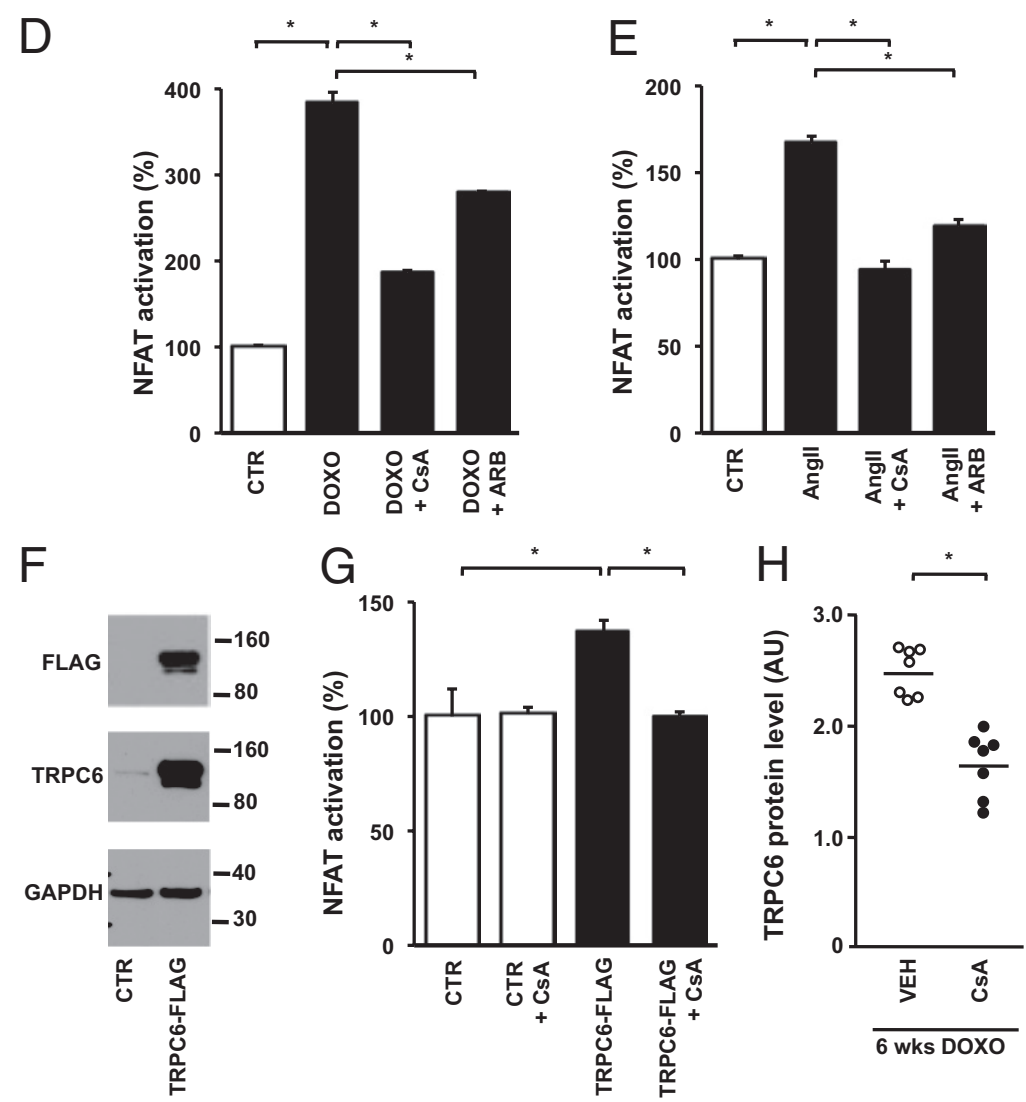

Figure 5. Effect of calcineurin inhibition on doxorubicin (DOXO)- and AngII-induced TRPC6 transcription and NFAT activation. TRPC6 mRNA levels in untreated cultured podocytes (CTR) and podocytes incubated with DOXO, as well as podocytes (co)-incubated with DOXO and the calcineurin inhibitor cyclosporine (CsA) (A). The effect of CsA on TRPC6 mRNA levels in AngII-exposed podocytes (B). The induction of NFAT activation in response to PAN was determined using a nuclear NFAT-responsive luciferase reporter construct; thereafter, the effects of the calcineurin inhibitors CsA and tacrolimus (Tac) were studied $(\mathbf{C})$. The effect of DOXO (D) and AngII (E) treatment on NFAT-controlled luciferase expression was determined, as well as after co-treatment with CsA and losartan (ARB). Western blot analysis of total lysates of cultured podocytes infected with a TRPC6-FLAG construct or empty vector (CTR) for FLAG and TRPC6 (F). The GAPDH blot shows equal protein loading. NFAT activation was determined in podocytes infected with a TRPC6-FLAG construct or empty vector in the presence or absence of CsA (G). $n=5$ to 6 separate podocyte cultures per experimental condition for all experiments. Glomerular TRPC6 expression was determined in vehicle-treated doxorubicin nephropathy rats (VEH) and CsA-treated doxorubicin nephropathy rats $(\mathbf{H}) .{ }^{*} P<0.05$. induced overexpression of a constitutively active NFATc1 variant (NFATC1 ${ }^{\text {nuc }}$ ) in podocytes of adult transgenic mice. In NFATc $1^{\text {nuc }}$, the serine residues that are dephosphorylated by calcineurin are mutated to alanines, rendering this NFATc1 mutant form constitutively nuclear and insensitive to nuclear kinases. ${ }^{27}$ We crossed an inducible transgenic mouse line expressing NFATc $1^{\text {nuc }}$ under the control of a tetracycline-responsive element with podocin-rtTA mice, which express the rtTA, specifically in podocytes. ${ }^{26,28}$ The resulting double transgenic offspring were administered doxycycline for 4 days, and transgene expression in isolated glomeruli was monitored by RTPCR. Only doxycycline-treated double transgenic mice expressed the NFATC1 ${ }^{\text {nuc }}$ transgene, whereas vehicletreated double transgenic mice (data not shown) or doxycycline-treated single transgenic mice, both used as negative controls, did not (Figure 7A). Importantly, mice expressing the NFATC $1^{\text {nuc }}$ transgene developed significant proteinuria (Figure 7, B and C) and showed significantly elevated TRPC6 protein levels in isolated glomeruli when compared with control animals (Figure 7, D and E). This experiment shows that NFAT activation in podocytes per se is sufficient to induce proteinuria in mice and that NFAT regulates TRPC6 expression in podocytes in vivo.

\section{Discussion}

In the present study we demonstrate that a deleterious positive feedback mechanism, in which TRPC6-mediated $\mathrm{Ca}^{2+}$ influx stimulates NFAT-dependent TRPC6 expression, is involved in Angll-associated podocyte injury. We show in different in vitro and in vivo models that Angll, a key contributor to the pathogenesis of glomerular dis- 

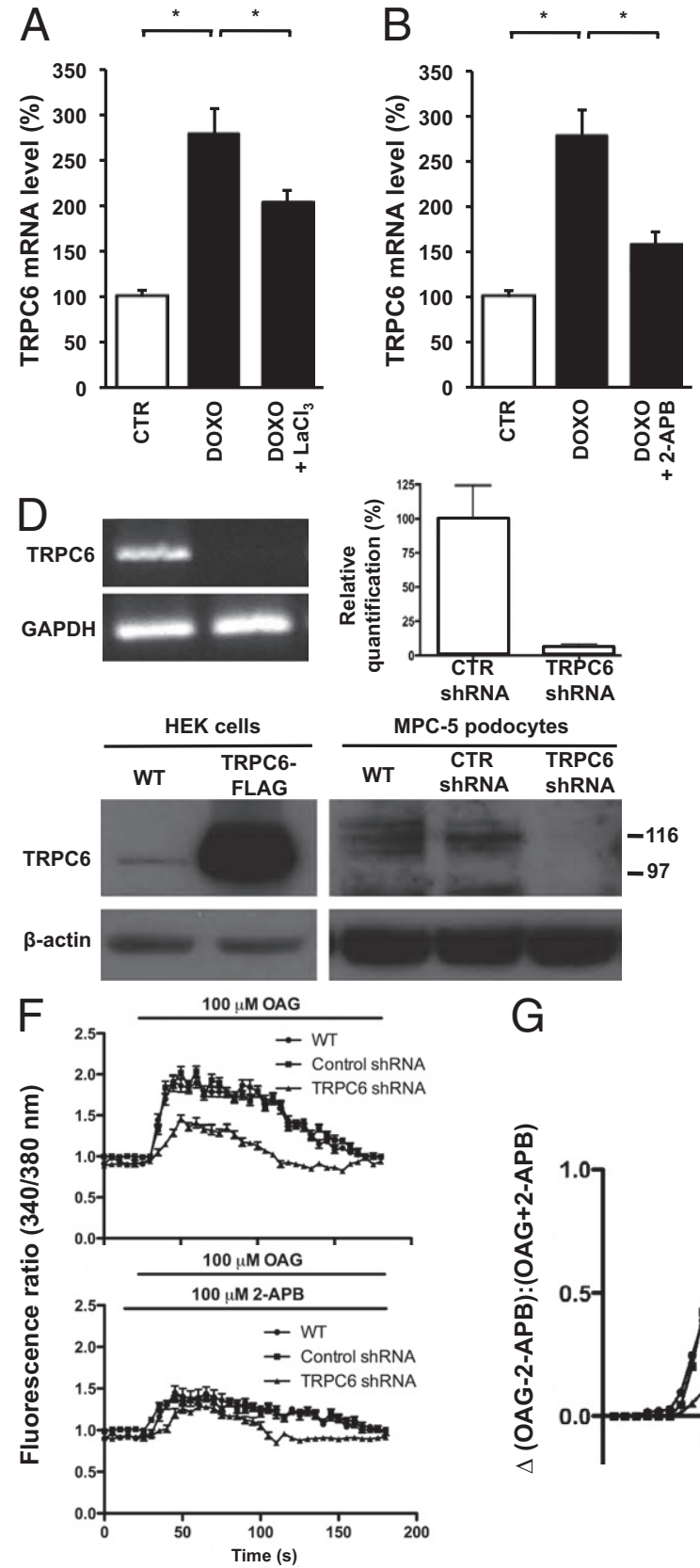

G

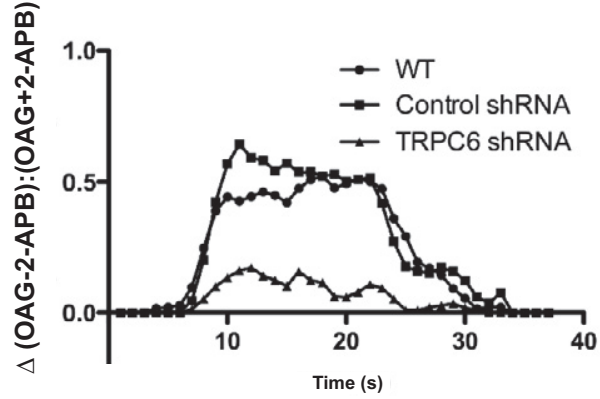

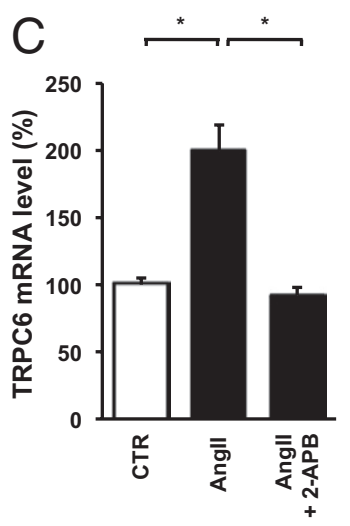

E

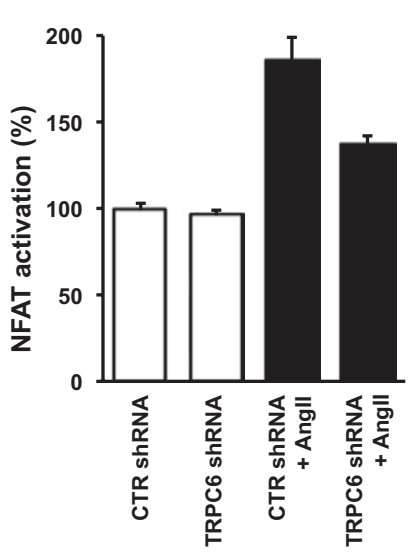
TRPC6 itself) on doxorubicin (DOXO) - and AngII-induced TRPC6 transcription and NFAT activation. TRPC6 mRNA levels in untreated cultured podocytes (CTR) and podocytes incubated with DOXO and DOXO-exposed podocytes coincubated with $\mathrm{LaCl}_{3}$ (DOXO $+\mathrm{LaCl}_{3}$ ), which inhibits $\mathrm{Ca}^{2+}$ influx (A). The effect of $2-\mathrm{APB}$, a TRPC channel blocker, on TRPC6 mRNA levels was evaluated in DOXO- (B) and AngII-treated (C) podocytes. Validation of a podocyte cell line stably transfected with a TRPC6 shRNA construct (D). TRPC6 knockdown was confirmed using semiquantitative RT-PCR, quantitative real-time PCR, and on the protein level Western blot analysis. We determined the effect of AngII on NFAT activation in these podocytes stably expressing a TRPC6 shRNA silencing construct or a control shRNA construct (CTR) (E). $n=3$ to 6 separate podocyte cultures per experimental condition for all experiments. ${ }^{*} P<0.05$. The OAG-induced $\mathrm{Ca}^{2+}$ response was determined by Fura-2 ratiometry in untransfected podocytes (WT), podocytes stably expressing a TRPC6 shRNA silencing construct, or a CTR shRNA construct, in either the absence or presence of 2-APB (F). The net effect of 2-APB on the OAG-induced $\mathrm{Ca}^{2+}$ response is depicted by calculating the ratio of the change in OAG-induced $\mathrm{Ca}^{2+}$ response in the absence and presence of 2-APB (G). ease, increases TRPC6 expression in podocytes. Glomerular TRPC6 expression was up-regulated by Angll infusion and in the Ren2 transgenic rat model for Angllassociated renal damage, an effect that was ameliorated by ARB treatment. TRPC6 expression was also enhanced in the doxorubicin nephropathy model for acquired progressive glomerular damage and proteinuric disease and positively correlated with markers for podocyte and glomerular damage. Blocking the effect of Angll in doxorubicin-induced in vitro podocyte injury and in vivo glomerular disease down-regulated TRPC6 expression and ameliorated glomerular damage and proteinuria. Thus, doxorubicin-induced TRPC6 expression in podocytes is mediated through Angll/AT1R signaling. Doxorubicin-induced and Angll-mediated TRPC6 transcription appears to be controlled by the $\mathrm{Ca}^{2+}$-dependent calcineurin/NFAT pathway, involving $\mathrm{Ca}^{2+}$ influx through TRPC6 itself. Indeed, we demonstrate in a novel transgenic mouse model that podocyte-specific NFAT activation induces glomerular TRPC6 expression and severe proteinuria.

Doxorubicin induces glomerular injury in rats, giving rise to progressive proteinuria and loss of renal function. ${ }^{37}$ Glomerular TRPC6 expression was enhanced in the unilateral and bilateral doxorubicin nephropathy models for acquired glomerular disease. Because doxorubicin also increased TRPC6 mRNA and protein expression in cultured podocytes, we conclude that the increased TRPC6 expression is a direct result of doxorubicin acting on the podocyte. TRPC6 was detectable in healthy 

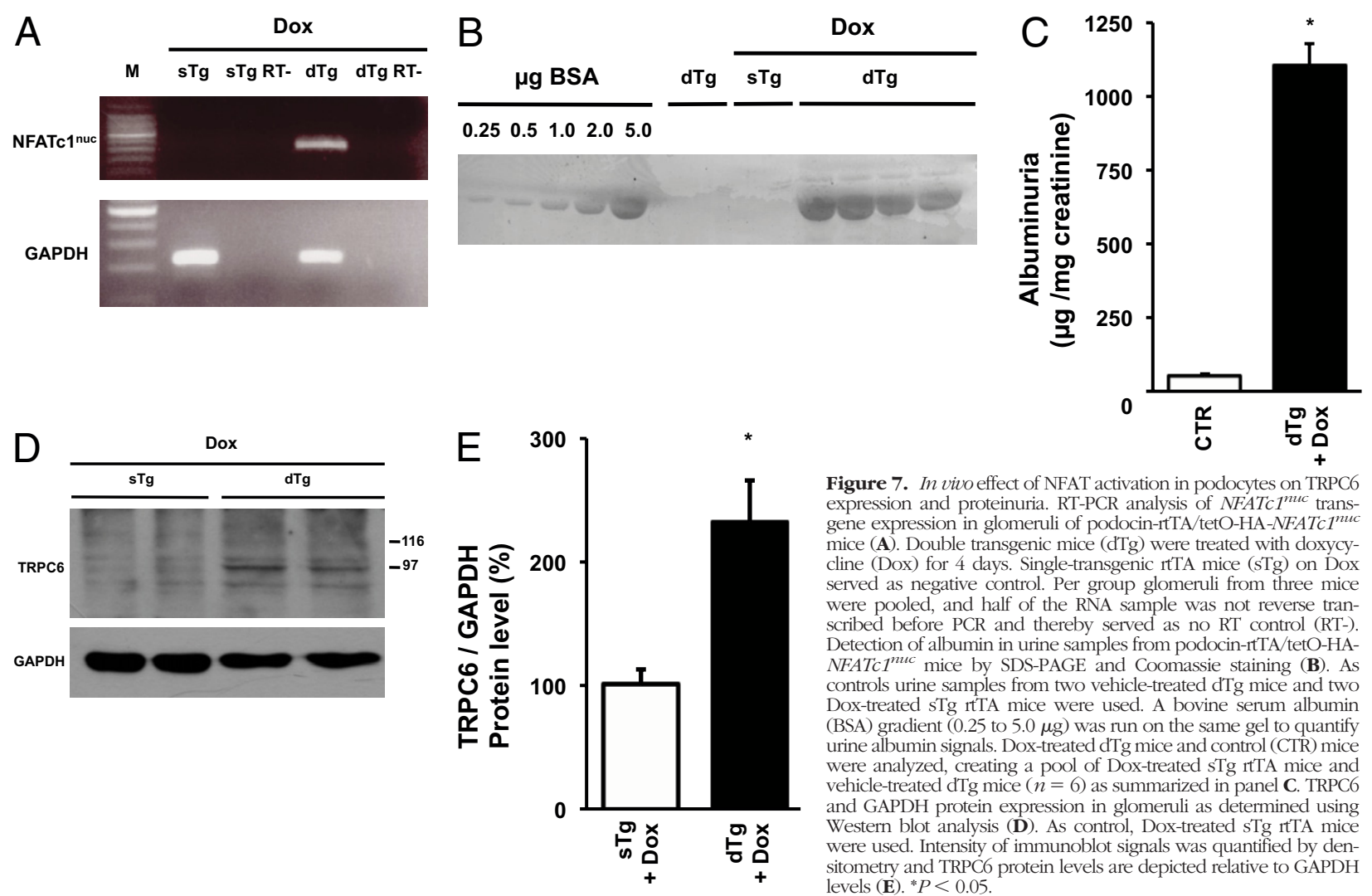

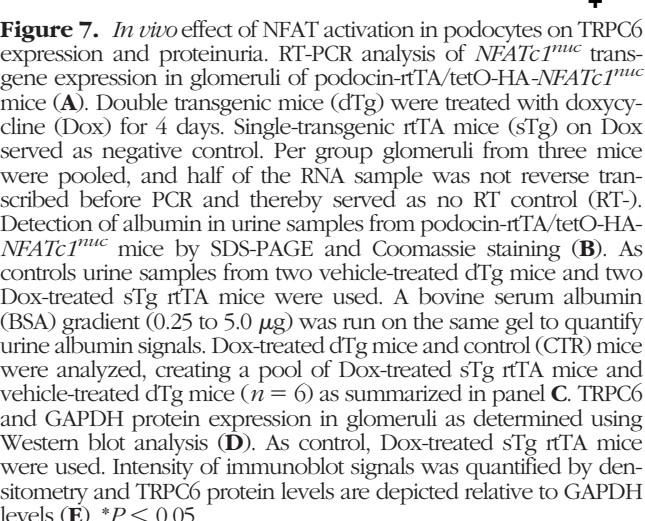

control animals but maximally enhanced in segmental glomerular lesions in doxorubicin nephropathy. These glomerular segments showed evidence of injury, where TRPC6 co-localizes with desmin as a marker for podocyte injury. Accordingly, glomerular TRPC6 expression showed a significant correlation with the extent of glomerulosclerosis. Because highly sclerotic glomeruli lacked TRPC6 expression, this correlation may be lost with advanced FGS when podocyte depletion occurs. The pathological characteristics of long-term doxorubicin nephropathy, including segmental glomerulosclerosis, closely resemble those seen in human FSGS. ${ }^{37}$ Thus, increased TRPC6 expression appears crucially involved in the pathogenesis of podocyte and glomerular damage, leading to glomerulosclerosis and proteinuria in FSGS. These findings are in line with increased TRPC6 expression in human acquired FSGS and TRPC6 gain-of-function mutations leading to hereditary FSGS. ${ }^{2-4}$

We demonstrate that Angll infusion enhances glomerular TRPC6 expression in rats and that Angll application directly regulates TRPC6 expression in podocytes. Furthermore, this study is the first to demonstrate that ARBs and ACEis, counteracting the effects of Angll, decrease TRPC6 overexpression in experimental glomerular disease. Because TRPC6 expression is enhanced in acquired human glomerular disease, and in the absence of specific TRPC6 blockers for clinical use, our data suggest that treatment with ARBs and ACEis are a potential way to reduce TRPC6 expression. ARBs and ACEis are known to reduce glomerular injury, decrease proteinuria, and ameliorate renal function decline in chronic renal disease, which is partly independent of their antihypertensive action. ${ }^{38}$ We and others have previously shown that the RAAS is involved in doxorubicin nephropathy, and the key pathological involvement of Angll in glomerular disease is widely accepted. ${ }^{19,39,40}$ Accordingly, we now demonstrate that doxorubicin-induced TRPC6 expression in podocytes is Angll-mediated. In doxorubicin nephropathy, ACEis down-regulated TRPC6 expression by its effect on the systemic but not the local podocyte RAAS. Furthermore, in the Ren2 transgenic model of Angll-mediated renal injury, TRPC6 levels were significantly enhanced, which appeared to be a direct effect of Angll exemplified by the partial normalization of its expression after short-term ARB treatment. Several lines of evidence support that Angll is injurious to podocytes. For example, transgenic rats overexpressing the AT1R on their podocytes show structural podocyte damage and proteinuria, progressing to FSGS. ${ }^{24}$ Angll infusion reduces nephrin expression and provokes podocyte injury in experimental glomerulopathies, which is inhibited by RAAS blockade. ${ }^{30,41-45}$ Interestingly, adverse effects of Angll-mediated stimulation of TRPC6 have also been shown in nonrenal cells. ${ }^{14,18}$ Stimulation of TRPC6 by Angll plays an important role in vascular smooth muscle cell contraction, and TRPC6 expression in pulmonary vascular smooth muscle cell is increased in idiopathic pulmonary arterial hypertension. ${ }^{17,46,47}$ Importantly, Angll-induced $\mathrm{Ca}^{2+}$ influx through TRPC6 was shown to activate the calcineurin/NFAT signaling pathway and increase TRPC6 expression in cardiomyocytes, resulting in 


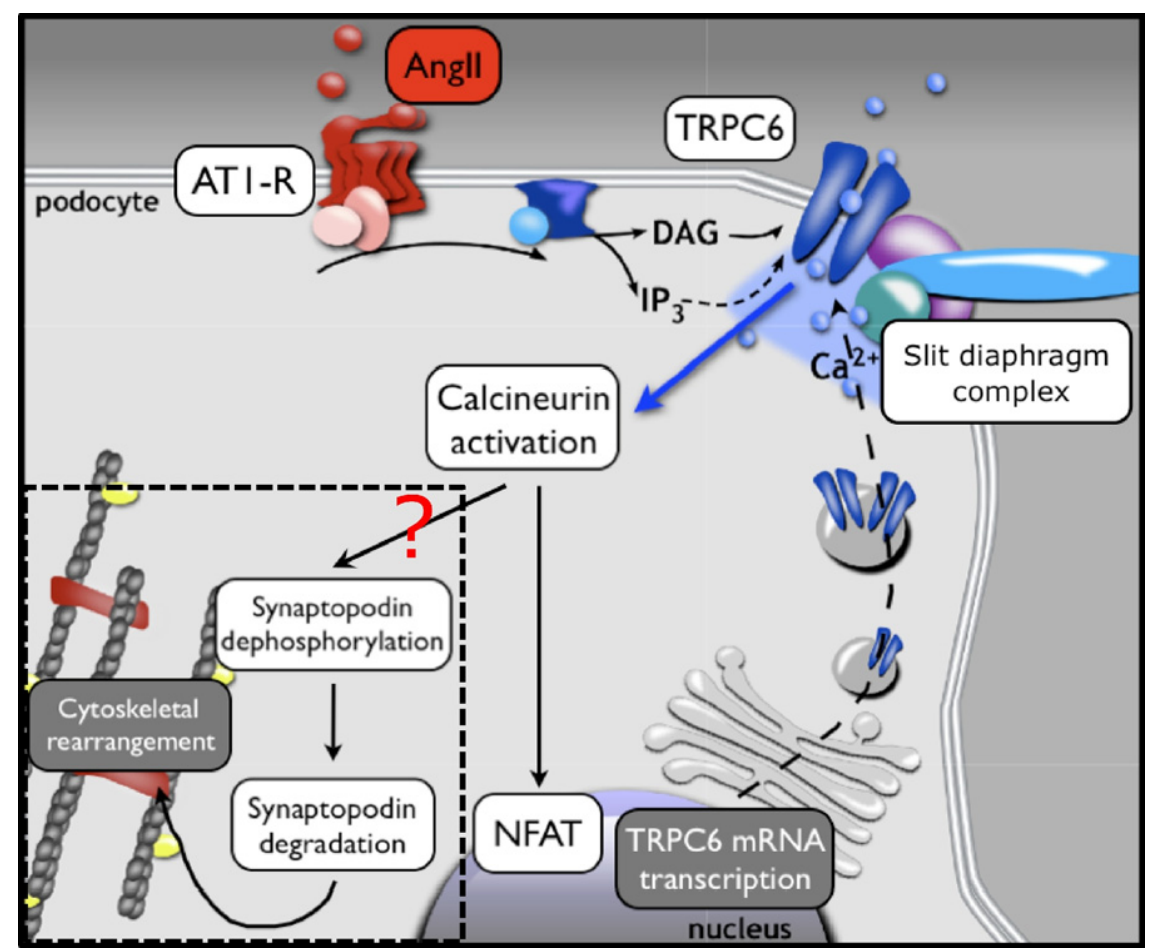

Figure 8. Proposed signaling pathway that regulates the in AngII-dependent TRPC6 expression in podocytes. Results from our study together with previously published data ${ }^{57}$ suggest the existence of the following signaling pathways in podocytes mediating AngII-induced TRPC6 expression and podocyte injury. AT1R stimulation by AngII results in $\mathrm{Ca}^{2+}$ influx at least in part mediated by TRPC6. $\mathrm{Ca}^{2+}$-dependent calcineurin activation leads to activation and nuclear translocation of NFAT, which enhances transcription of NFAT-responsive genes such as TRPC6. A consequent increase in TRPC6 protein expression at the cell membrane could result in a positive feedback regulatory circuit, because $\mathrm{Ca}^{2+}$ influx through TRPC6 itself appears to be involved in the signaling pathway leading to increased TRPC6 expression. Our studies show that NFAT activation per se is sufficient to induce TRPC6 transcription and proteinuria. Hypothetically, the proposed feedback mechanism could also result in a persistent calcineurin activation, which was previously demonstrated to lead to the dephosphorylation and degradation of the actin-binding protein synaptopodin (dashed box). ${ }^{57}$ The latter was shown to result in cytoskeletal rearrangement and, eventually, proteinuria. Possibly, the latter pathway is involved in the generation of podocyte injury subsequent to AngII-induced TRPC6 expression. cardiomyocyte hypertrophy. ${ }^{14,18}$ A recent study by Eckel et $\mathrm{al}^{48}$ showed that Angll-induced albuminuria was not prevented but was significantly ameliorated in TRPC6 knockout compared with wild-type mice. Altogether, this demonstrates that Angll-induced and calcineurin/NFATmediated TRPC6 expression in the podocyte is an important mediator in the pathogenesis of podocyte injury and glomerular disease.

Thus, we hypothesized that the $\mathrm{Ca}^{2+}$ influx-stimulated calcineurin/NFAT pathway is involved in downstream signaling activated by Angll in the podocyte (proposed model depicted in Figure 8). The inhibitor of TRPC channel activity 2-APB reduced receptor-mediated $\mathrm{Ca}^{2+}$ influx into cultured podocytes, as well as doxorubicin-induced and Angll-mediated TRPC6 up-regulation. This demonstrates that TRPC6 expression is $\mathrm{Ca}^{2+}$-dependent and that $\mathrm{Ca}^{2+}$ influx through TRPC channels could be involved. It was previously shown that Angll induces elevation of $\left[\mathrm{Ca}^{2+}\right]_{\mathrm{i}}$ in the podocyte by influx from the extracellular compartment, which can be blocked by ARBs. ${ }^{21-23}$ Among other downstream targets, $\mathrm{Ca}^{2+}$ influx activates the serine-threonine phosphatase calcineurin, which dephosphorylates the NFAT family of transcription factors, leading to the transcription of NFAT-responsive genes. ${ }^{49}$ We demonstrated that Angll activates NFAT in podocytes and that calcineurin inhibition and blocking of the AT1R inhibit doxorubicin-induced and Angll-mediated NFAT activation and TRPC6 expression. The TRPC6 promoter harbors two conserved NFAT-responsive sites, required for TRPC6 transcription in response to $\mathrm{Ca}^{2+}$ dependent calcineurin/NFAT signaling in cardiomyocytes. ${ }^{14}$ Schlondorff et $\mathrm{al}^{36}$ have shown that introduction of a gain-of-function TRPC6 mutant in podocytes enhances NFAT activation in vitro. Furthermore, they re- ported that cyclosporine, without directly affecting TRPC6 channel activity, inhibits TRPC6-mediated NFAT signaling. ${ }^{36}$ Thus, $\mathrm{Ca}^{2+}$ influx through TRPC6 itself could play a role in an AT1R-stimulated calcineurin/NFAT signaling cascade. This hypothesis is supported by our data showing that lentiviral TRPC6 overexpression in podocytes activates NFAT in an AT1R- and calcineurin-dependent manner. Importantly, we also demonstrated that TRPC6 knockdown decreases $\mathrm{Ca}^{2+}$ influx and inhibits Angll-induced NFAT activation in podocytes. In line with these data, it was recently shown that in podocytes isolated from TRPC6 knockout and wild-type mice the response to Angll significantly differs, showing a reduced $\mathrm{Ca}^{2+}$ current in the TRPC6 knockout podocytes. ${ }^{48}$ In a similar TRPC6 shRNA approach, Greka and coworkers ${ }^{50}$ recently showed that down-regulation of TRPC6 reduces Angll-evoked $\mathrm{Ca}^{2+}$ transients in podocytes, along with effects on the podocyte cytoskeleton. The residual NFAT activation in our experiments might be related to remaining TRPC6 expression but could also mean that the cascade is not solely TRPC6 dependent and other (TRPC) $\mathrm{Ca}^{2+}$ channels or influx mechanisms are involved. Expression of other TRPC channels in the podocyte has been shown, and TRP channels form heterotetramers in which different TRP subunits combined form functional channels. ${ }^{51-53}$

Altogether, our data are the first to demonstrate that Angll induces a calcineurin/NFAT pathway in podocytes that appears to be dependent on $\mathrm{Ca}^{2+}$ influx through TRPC6 and, in addition, leads to enhanced expression of TRPC6 itself, thus forming a potentially deleterious feedback loop. Zhang et $\mathrm{al}^{54}$ previously suggested that Angllinduced TRPC6 expression might involve MAPK, ERK, $\mathrm{JNK}$, and $\mathrm{NF}-\kappa \mathrm{B}$. In cardiomyocytes, those pathways 
were also described, and receptor-activated TRPC6-mediated NFAT activation was shown to inhibit JNK and ERK. ${ }^{55}$ To demonstrate that NFAT activation in podocytes is independently capable of enhancing TRPC6 expression in vivo and inducing proteinuria, we generated a transgenic mouse model in which a constitutively active NFAT mutant could be induced in a podocyte-specific manner. As originally hypothesized, we demonstrated that induction of NFAT results in increased glomerular TRPC6 expression and the development of severe proteinuria. On submission of this work another article appeared ${ }^{56}$ that also describes the effect of NFAT overexpression and the subsequent development of proteinuria; however, the involvement of TRPC6 was not specifically studied in that article. Our data confirm that the activation of NFAT in podocytes is sufficient to induce proteinuria and substantiate that a positive feedback loop involving NFAT-induced TRPC6 expression contributes to the induction and/or maintenance of proteinuric disease.

The current findings add an additional downstream pathway secondary to calcineurin signaling in podocytes, in addition to the dephosphorylation of the actinbinding protein synaptopodin by calcineurin as we previously reported. ${ }^{57}$ Synaptopodin is vitally important in maintaining the podocyte actin cytoskeleton, and its dephosphorylation results in subsequent cathepsin L-mediated degradation, cytoskeletal disorganization, and proteinuria. ${ }^{57,58}$ Thus, our data contribute to a hypothetical mechanism by which Angll-induced and NFAT-mediated TRPC6 overexpression, as addressed in our experiments, fuel persistent calcineurin activation, leading to synaptopodin degradation as described previously, eventually perpetuating podocyte injury (Figure 8). For this hypothesis to be proven, it remains to be established whether $\mathrm{Ca}^{2+}$ influx through TRPC6 directly induces calcineurin-mediated dephosphorylation of synaptopodin.

In conclusion, we have demonstrated an Angll-induced, TRPC6-dependent, NFAT-mediated feedback mechanism driving TRPC6 transcription in podocytes. This finding underlines the crucial role of TRPC6 in the pathogenesis of podocyte injury and proteinuria.

\section{References}

1. Faul C, Asanuma K, Yanagida-Asanuma E, Kim K, Mundel P: Actin up: regulation of podocyte structure and function by components of the actin cytoskeleton. Trends Cell Biol 2007, 17:428-437

2. Reiser J, Polu KR, Moller CC, Kenlan P, Altintas MM, Wei C, Faul C, Herbert S, Villegas I, Avila-Casado C, McGee M, Sugimoto H, Brown D, Kalluri R, Mundel P, Smith PL, Clapham DE, Pollak MR: TRPC6 is a glomerular slit diaphragm-associated channel required for normal renal function. Nat Genet 2005, 37:739-744

3. Winn MP, Conlon PJ, Lynn KL, Farrington MK, Creazzo T, Hawkins AF, Daskalakis N, Kwan SY, Ebersviller S, Burchette JL, PericakVance MA, Howell DN, Vance JM, Rosenberg PB: A mutation in the TRPC6 cation channel causes familial focal segmental glomerulosclerosis. Science 2005, 308:1801-1804

4. Moller CC, Wei C, Altintas MM, Li J, Greka A, Ohse T, Pippin JW Rastaldi MP, Wawersik S, Schiavi S, Henger A, Kretzler M, Shankland SJ, Reiser J: Induction of TRPC6 channel in acquired forms of proteinuric kidney disease. J Am Soc Nephrol 2007, 18:29-36
5. Krall P, Canales CP, Kairath P, Carmona-Mora P, Molina J, Carpio JD Ruiz P, Mezzano SA, Li J, Wei C, Reiser J, Young JI, Walz K: Podocyte-specific overexpression of wild type or mutant trpc6 in mice is sufficient to cause glomerular disease. PLoS One 2010, 5:e12859

6. Clapham DE: TRP channels as cellular sensors. Nature 2003, 426 517-524

7. Hsu YJ, Hoenderop JG, Bindels RJ: TRP channels in kidney disease Biochim Biophys Acta 2007, 1772:928-936

8. Nijenhuis T, Vallon V, van der Kemp AW, Loffing J, Hoenderop JG, Bindels RJ: Enhanced passive $\mathrm{Ca} 2+$ reabsorption and reduced Mg2+ channel abundance explains thiazide-induced hypocalciuria and hypomagnesemia. J Clin Invest 2005, 115:1651-1658

9. Woudenberg-Vrenken TE, Bindels RJ, Hoenderop JG: The role of transient receptor potential channels in kidney disease. Nat Rev Nephrol 2009, 5:441-449

10. Moller CC, Flesche J, Reiser J: Sensitizing the slit diaphragm with TRPC6 ion channels. J Am Soc Nephrol 2009, 20:950-953

11. Zhu B, Chen N, Wang ZH, Pan XX, Ren H, Zhang W, Wang WM: Identification and functional analysis of a novel TRPC6 mutation associated with late onset familial focal segmental glomerulosclerosis in Chinese patients. Mutat Res 2009, 664:84-90

12. Santin S, Ars E, Rossetti S, Salido E, Silva I, Garcia-Maset R, Gimenez I, Ruiz P, Mendizabal S, Nieto JL, Pena A, Camacho JA, Fraga G, Cobo MA, Bernis C, Ortiz A, de Pablos AL, Sanchez-Moreno A, Pintos G, Mirapeix E, Fernandez-Llama P, Ballarin J, Torra R: TRPC6 mutational analysis in a large cohort of patients with focal segmental glomerulosclerosis. Nephrol Dial Transplant 2009, 24: 3089-3096

13. Hofmann T, Obukhov AG, Schaefer M, Harteneck C, Gudermann T, Schultz G: Direct activation of human TRPC6 and TRPC3 channels by diacylglycerol. Nature 1999, 397:259-263

14. Kuwahara K, Wang Y, McAnally J, Richardson JA, Bassel-Duby R, Hill JA, Olson EN: TRPC6 fulfills a calcineurin signaling circuit during pathologic cardiac remodeling. J Clin Invest 2006, 116:3114-3126

15. Ruggenenti P, Perna A, Gherardi G, Garini G, Zoccali C, Salvadori M, Scolari F, Schena FP, Remuzzi G: Renoprotective properties of ACEinhibition in non-diabetic nephropathies with non-nephrotic proteinuria. Lancet 1999, 354:359-364

16. Ruggenenti P, Perna A, Loriga G, Ganeva M, Ene-lordache B, Turturro M, Lesti M, Perticucci E, Chakarski IN, Leonardis D, Garini G, Sessa A, Basile C, Alpa M, Scanziani R, Sorba G, Zoccali C, Remuzzi G: Blood-pressure control for renoprotection in patients with nondiabetic chronic renal disease (REIN-2): multicentre, randomised controlled trial. Lancet 2005, 365:939-946

17. Saleh SN, Albert AP, Peppiatt CM, Large WA: Angiotensin II activates two cation conductances with distinct TRPC1 and TRPC6 channel properties in rabbit mesenteric artery myocytes. J Physiol 2006, 577:479-495

18. Onohara N, Nishida M, Inoue R, Kobayashi $H$, Sumimoto $H$, Sato $Y$, Mori Y, Nagao T, Kurose H: TRPC3 and TRPC6 are essential for angiotensin II-induced cardiac hypertrophy. EMBO J 2006, 25:53055316

19. van den Hoven MJ, Waanders F, Rops AL, Kramer $A B$, van Goor $H$, Berden JH, Navis G, van der Vlag J: Regulation of glomerular heparanase expression by aldosterone, angiotensin II and reactive oxygen species. Nephrol Dial Transplant 2009, 24:2637-2645

20. Harrison-Bernard LM, Navar LG, Ho MM, Vinson GP, el-Dahr SS: Immunohistochemical localization of ANG II AT1 receptor in adult rat kidney using a monoclonal antibody. Am J Physiol 1997, 273: F170-177

21. Henger A, Huber T, Fischer KG, Nitschke R, Mundel P, Schollmeyer $P$, Greger R, Pavenstadt H: Angiotensin II increases the cytosolic calcium activity in rat podocytes in culture. Kidney Int 1997, 52:687693

22. Nitschke R, Henger A, Ricken S, Gloy J, Muller V, Greger R, Pavenstadt $\mathrm{H}$ : Angiotensin II increases the intracellular calcium activity in podocytes of the intact glomerulus. Kidney Int 2000, 57:41-49

23. Gloy J, Henger A, Fischer KG, Nitschke R, Mundel P, Bleich M, Schollmeyer P, Greger R, Pavenstadt H: Angiotensin II depolarizes podocytes in the intact glomerulus of the rat. J Clin Invest 1997 99:2772-2781

24. Hoffmann S, Podlich D, Hahnel B, Kriz W, Gretz N: Angiotensin II type 1 receptor overexpression in podocytes induces glomerulosclerosis in transgenic rats. J Am Soc Nephrol 2004, 15:1475-1487 
25. Huby AC, Rastaldi MP, Caron K, Smithies O, Dussaule JC, Chatziantoniou C: Restoration of podocyte structure and improvement of chronic renal disease in transgenic mice overexpressing renin. PLoS One 2009, 4:e6721

26. Winslow MM, Pan M, Starbuck M, Gallo EM, Deng L, Karsenty G, Crabtree GR: Calcineurin/NFAT signaling in osteoblasts regulates bone mass. Dev Cell 2006, 10:771-782

27. Beals CR, Clipstone NA, Ho SN, Crabtree GR: Nuclear localization of NF-ATc by a calcineurin-dependent, cyclosporin-sensitive intramolecular interaction. Genes Dev 1997, 11:824-834

28. Shigehara T, Zaragoza C, Kitiyakara C, Takahashi H, Lu H, Moeller M, Holzman LB, Kopp JB: Inducible podocyte-specific gene expression in transgenic mice. J Am Soc Nephrol 2003, 14:1998-2003

29. van den Born J, van den Heuvel LP, Bakker MA, Veerkamp JH, Assmann KJ, Berden JH: A monoclonal antibody against GBM HS induces an acute selective proteinuria in rats. Kidney Int 1992, 41: 115-123

30. Raats CJ, Bakker MA, Hoch W, Tamboer WP, Groffen AJ, van den Heuvel LP, Berden JH, van den Born J: Differential expression of agrin in renal basement membranes as revealed by domain-specific antibodies. J Biol Chem 1998, 273:17832-17838

31. Shankland SJ, Pippin JW, Reiser J, Mundel P: Podocytes in culture: past, present, and future. Kidney Int 2007, 72:26-36

32. Lee MA, Bohm M, Paul M, Bader M, Ganten U, Ganten D: Physiological characterization of the hypertensive transgenic rat TGR(mREN2)27. Am J Physiol 1996, 270:E919-929

33. Ichihara A, Kaneshiro Y, Takemitsu T, Sakoda M, Itoh H: The (pro)renin receptor and the kidney. Semin Nephrol 2007, 27:524-528

34. Durvasula RV, Petermann AT, Hiromura K, Blonski M, Pippin J, Mundel P, Pichler R, Griffin S, Couser WG, Shankland SJ: Activation of a local tissue angiotensin system in podocytes by mechanical strain. Kidney Int 2004, 65:30-39

35. Durvasula RV, Shankland SJ: Activation of a local renin angiotensin system in podocytes by glucose. Am J Physiol Renal Physiol 2008, 294:F830-839

36. Schlondorff J, Del Camino D, Carrasquillo R, Lacey V, Pollak MR: TRPC6 mutations associated with focal segmental glomerulosclerosis cause constitutive activation of NFAT-dependent transcription. Am J Physiol Cell Physiol 2009, 296:C558-569

37. Pippin JW, Brinkkoetter PT, Cormack-Aboud FC, Durvasula RV, Hauser PV, Kowalewska J, Krofft RD, Logar CM, Marshall CB, Ohse T, Shankland SJ: Inducible rodent models of acquired podocyte diseases. Am J Physiol Renal Physiol 2009, 296:F213-229

38. Reiser J, Mundel P: Dual effects of RAS blockade on blood pressure and podocyte function. Curr Hypertens Rep 2007, 9:403-408

39. Kramer A, van den Hoven M, Rops A, Wijnhoven T, van den Heuvel L, Lensen J, van Kuppevelt T, van Goor H, van der Vlag J, Navis G, Berden $\mathrm{JH}$ : Induction of glomerular heparanase expression in rats with adriamycin nephropathy is regulated by reactive oxygen species and the renin-angiotensin system. J Am Soc Nephrol 2006, 17:2513-2520

40. Kramer AB, van der Meulen EF, Hamming I, van Goor H, Navis G Effect of combining ACE inhibition with aldosterone blockade on proteinuria and renal damage in experimental nephrosis. Kidney Int 2007, 71:417-424

41. Hiramatsu N, Hiromura K, Shigehara T, Kuroiwa T, Ideura $H$, Sakura N, Takeuchi S, Tomioka M, Ikeuchi H, Kaneko Y, Ueki K, Kopp JB, Nojima Y: Angiotensin II type 1 receptor blockade inhibits the development and progression of HIV-associated nephropathy in a mouse model. J Am Soc Nephrol 2007, 18:515-527

42. Ideura H, Hiromura K, Hiramatsu N, Shigehara T, Takeuchi S, Tomioka M, Sakairi T, Yamashita S, Maeshima A, Kaneko Y, Kuroiwa T, Kopp JB, Nojima Y: Angiotensin II provokes podocyte injury in murine model of HIV-associated nephropathy. Am J Physiol Renal Physiol 2007, 293:F1214-1221
43. Benigni A, Tomasoni S, Gagliardini E, Zoja C, Grunkemeyer JA, Kalluri R, Remuzzi G: Blocking angiotensin II synthesis/activity preserves glomerular nephrin in rats with severe nephrosis. J Am Soc Nephrol 2001, 12:941-948

44. Remuzzi A, Gagliardini E, Sangalli F, Bonomelli M, Piccinelli M, Benigni A, Remuzzi G: ACE inhibition reduces glomerulosclerosis and regenerates glomerular tissue in a model of progressive renal disease. Kidney Int 2006, 69:1124-1130

45. Kawachi $H$, Koike $H$, Shimizu F: Molecular structure and function of the slit diaphragm: expression of nephrin in proteinuric states and in developing glomeruli. Nephrol Dial Transplant 2002, 17 Suppl 9:20-22

46. Weissmann N, Dietrich A, Fuchs B, Kalwa H, Ay M, Dumitrascu R, Olschewski A, Storch U, Mederos y Schnitzler M, Ghofrani HA, Schermuly RT, Pinkenburg O, Seeger W, Grimminger F, Gudermann T: Classical transient receptor potential channel 6 (TRPC6) is essential for hypoxic pulmonary vasoconstriction and alveolar gas exchange. Proc Natl Acad Sci U S A 2006, 103:19093-19098

47. Yu Y, Fantozzi I, Remillard CV, Landsberg JW, Kunichika N, Platoshyn O, Tigno DD, Thistlethwaite PA, Rubin LJ, Yuan JX: Enhanced expression of transient receptor potential channels in idiopathic pulmonary arterial hypertension. Proc Natl Acad Sci U S A 2004, 101: 13861-13866

48. Eckel J, Lavin PJ, Finch EA, Mukerji N, Burch J, Gbadegesin R, Wu G, Bowling B, Byrd A, Hall G, Sparks M, Zhang ZS, Homstad A, Barisoni L, Birbaumer L, Rosenberg P, Winn MP: TRPC6 enhances angiotensin II-induced albuminuria. J Am Soc Nephrol 2011, 22:526-535

49. Gwack Y, Feske S, Srikanth S, Hogan PG, Rao A: Signalling to transcription: store-operated $\mathrm{Ca} 2+$ entry and NFAT activation in lymphocytes. Cell Calcium 2007, 42:145-156

50. Tian D, Jacobo SM, Billing D, Rozkalne A, Gage SD, Anagnostou T, Pavenstadt H, Hsu HH, Schlondorff J, Ramos A, Greka A: Antagonistic regulation of actin dynamics and cell motility by TRPC5 and TRPC6 channels. Sci Signal 2010, 3:ra77

51. Goel M, Sinkins WG, Zuo CD, Estacion M, Schilling WP: Identification and localization of TRPC channels in the rat kidney. Am J Physiol Renal Physiol 2006, 290:F1241-1252

52. Hoenderop JG, Voets T, Hoefs S, Weidema F, Prenen J, Nilius B, Bindels RJ: Homo- and heterotetrameric architecture of the epithelial Ca2+ channels TRPV5 and TRPV6. EMBO J 2003, 22:776-785

53. Hofmann T, Schaefer M, Schultz G, Gudermann T: Subunit composition of mammalian transient receptor potential channels in living cells. Proc Natl Acad Sci U S A 2002, 99:7461-7466

54. Zhang H, Ding J, Fan Q, Liu S: TRPC6 up-regulation in Ang Il-induced podocyte apoptosis might result from ERK activation and NF\{kappa\}B translocation. Exp Biol Med (Maywood) 2009, 234: 1029-1036

55. Nishida M, Onohara N, Sato Y, Suda R, Ogushi M, Tanabe S, Inoue R, Mori Y, Kurose H: Galpha12/13-mediated up-regulation of TRPC6 negatively regulates endothelin-1-induced cardiac myofibroblast formation and collagen synthesis through nuclear factor of activated $T$ cells activation. J Biol Chem 2007, 282:23117-23128

56. Wang Y, Jarad G, Tripathi P, Pan M, Cunningham J, Martin DR, Liapis $\mathrm{H}$, Miner $\mathrm{JH}$, Chen F: Activation of NFAT signaling in podocytes causes glomerulosclerosis. J Am Soc Nephrol 2010, 21:1657-1666

57. Faul C, Donnelly M, Merscher-Gomez S, Chang YH, Franz S, Delfgaauw J, Chang JM, Choi HY, Campbell KN, Kim K, Reiser J, Mundel $\mathrm{P}$ : The actin cytoskeleton of kidney podocytes is a direct target of the antiproteinuric effect of cyclosporine A. Nat Med 2008, 14:931-938

58. Asanuma K, Kim K, Oh J, Giardino L, Chabanis S, Faul C, Reiser J, Mundel P: Synaptopodin regulates the actin-bundling activity of alpha-actinin in an isoform-specific manner. J Clin Invest 2005, 115 : $1188-1198$ 